Pascual A M, Romero M L, Tizani W. Thermal behaviour of blind-bolted connections to hollow and concrete-filled steel tubular columns. Journal of constructional steel research 2015;107:137-149.

http://dx.doi.org/10.1016/j.jcsr.2015.01.014

\title{
Thermal behaviour of blind-bolted connections to hollow and concrete- filled steel tubular columns
}

\author{
Ana M. Pascual ${ }^{\text {a }}$, Manuel L. Romero ${ }^{\mathrm{a}, *}$, Walid Tizani ${ }^{\mathrm{b}}$ \\ ${ }^{a}$ Instituto de Ciencia y Tecnología del Hormigón (ICITECH), \\ Universitat Politècnica de València, Valencia, Spain \\ ${ }^{b}$ Department of Civil Engineering, The University of Nottingham,UK \\ *Corresponding author.e-mail address: mromero@mes.upv.es
}

\section{ABSTRACT}

This paper reports on the thermal analysis of blind-bolts connected to concrete filled steel tube (CFST) and hollow steel section (HSS) columns. The aim is therefore the investigation of the temperature distribution in the connected sections and the evaluation of the effects due to concrete filling and anchored bolt extension. For this purpose, experimental and numerical work was carried out. The test program involved twelve small-scale unloaded specimens where the variables were: tube section dimensions, type of blind-bolt, and hollow or concrete filled steel tubes. Results from the experiments revealed the noteworthy effect of concrete on bolt temperature reduction, the insignificant influence of tube section dimensions, and the limited impact of embedded bolt extension. Finite element models (FEM) of connections were developed to simulate the behaviour of tested pieces. Comparison with tests allowed the calibration of thermal material properties and characteristics of heat flux in interactions. Furthermore, assessments of heat transfer problem on the simulation of small-scale pieces extended to the numerical model of the whole endplate connection between an I-beam and a 
Pascual A M, Romero M L, Tizani W. Thermal behaviour of blind-bolted connections to hollow and concrete-filled steel tubular columns. Journal of constructional steel research 2015;107:137-149.

http://dx.doi.org/10.1016/j.jcsr.2015.01.014

tubular column. Finally, the suitability of simple methods from Eurocode 3 Part 1.2 and other references to obtain the temperature on the connection was evaluated.

Keywords: Thermal analysis; Blind-bolt; Anchored extensions; Concrete filled steel tube;

Finite element model; Eurocode 3.

\section{NOTATION}

$\begin{array}{ll}\text { A/V } & \text { Section factor } \\ \text { CFST } & \text { Concrete filled steel tube } \\ \text { D } & \text { height of the beam } \\ \text { EC3 } & \text { Eurocode 3. Part 1.2 } \\ \text { EC4 } & \text { Eurocode 4. Part 1.2 } \\ \text { EXP } & \text { Experimental } \\ \text { EHB } & \text { Extended Hollo-bolt fastener system } \\ \text { FEA } & \text { Finite element analysis } \\ \text { FEM } & \text { Finite element model } \\ f_{c} & \text { Compressive cylinder strength of concrete at room temperature } \\ f_{y} & \text { Yield strength of structural steel at room temperature } \\ f_{u} & \text { Ultimate strength of structural steel at room temperature } \\ \text { HSS } & \text { Hollow steel section } \\ \text { HB } & \text { Hollo-bolt fastener system } \\ \mathrm{h} & \text { depth in the connection } \\ \mathrm{t} & \text { thickness of steel tube column } \\ \mathrm{UHB} & \text { Hollo-bolt in an unfilled section } \\ \theta & \text { temperature }\end{array}$


Pascual A M, Romero M L, Tizani W. Thermal behaviour of blind-bolted connections to hollow and concrete-filled steel tubular columns. Journal of constructional steel research 2015;107:137-149.

http://dx.doi.org/10.1016/j.jcsr.2015.01.014

\section{INTRODUCTION}

Besides the load bearing capacity, convenient aesthetical appearance and construction facilities, one of the most valuable advantages of CFST columns is its appropriate behaviour in fire. The concrete infill acts as a heat sink, which delays the rise of temperatures in the cross-section, at the same time that steel works as a shield and maintains the integrity of the element [1]. The thermal analysis of CFST columns has been covered in several researches, however, their connection with the beam is usually not studied. The lack of knowledge of the thermal behaviour of connection between the beam and column has made designers solve the problem by providing the same protection as in the elements joined. Nonetheless, catastrophic fires $[2,3]$ have demonstrated the crucial role of connections in the building failure and the necessity of its further study.

Up to now, the studies of fire behaviour of endplate bolted connections are scarce. Initially they were limited to joints between I-section steel beams and open sections steel columns. For instance, Al-Jabri et al. [4, 5] developed experimental and numerical work to produce relevant data and insight into flush endplate bolted steel connections at elevated temperatures. On the other hand, Wang et al. [6] and Dai et al.[7] carried out tests and simulations of 10 medium scale assemblies that included five different types of joints to open section steel columns. They studied the forces generated in connections during the fire due to restrained beam deformations.

In connections to CFST or HSS columns, the bolted solution has to use special fasteners able to be tightened from one side of the tube, called blind-bolts. Several types of blind-bolts exist, but Hollo-bolt system (Lindapter International, UK) was chosen for this study due to its easy assembly and its feasibility of resisting bending moments [8]. The Hollo-bolt is mainly 
Pascual A M, Romero M L, Tizani W. Thermal behaviour of blind-bolted connections to hollow and concrete-filled steel tubular columns. Journal of constructional steel research 2015; 107:137-149.

http://dx.doi.org/10.1016/j.jcsr.2015.01.014

made up of three parts (Fig. 1a): a standard bolt, a sleeve with four slots, and a cone with a threaded hole where the bolt is screwed. The Hollo-bolt works as follows [9]: firstly, the piece is inserted in the elements to join through clearance holes, then the bolt is tightened, so that the threaded cone moves against the inner face of the tube expanding the sleeve legs until the total clamping force is transmitted.

In recent years, the advantages of Hollo-bolt system have raised the interest of numerous researchers. Elghazouli et al. [10] studied, through experimental tests, angle connections between beam and tubular unfilled column by using Hollo-bolt under monotonic and cyclic loads. Their experimental program also included tension tests on the blind-bolts that gave notice of the tension behaviour of the bolt system. Liu et al $[11,12]$ examined the same type of connections first subjected to shear loads and then to axial loads. Column and angle thickness together with the distance between Hollo-bolt and beam flange, were the principal parameters that influenced joint capacity and deformation. Their studies comprised numerical analysis and component characterization with a good adjustment to the experimental results. In addition, strength and stiffness of Hollo-bolt system in a T-stub connection was assessed by Wang et al. [13], who aimed to obtain a theoretical expression in the framework of component method. They noted the higher flexibility introduced by the sleeve ductile behaviour.

A modification of this type of blind-bolt (Fig. 1b), called the Extended Hollo-bolt, was developed at the University of Nottingham $[8,14]$ in order to be used in CFST connections. The novelty was the use of a longer shank that ended in a screwed nut whose purpose was to take advantage of the concrete infill to improve the connection stiffness and be able to resist bending moments. Eight full-scale tests were carried out by Tizani et al. [8] on flush endplate 
Pascual A M, Romero M L, Tizani W. Thermal behaviour of blind-bolted connections to hollow and concrete-filled steel tubular columns. Journal of constructional steel research 2015;107:137-149.

http://dx.doi.org/10.1016/j.jcsr.2015.01.014

connection to CFST columns with Extended Hollo-bolt, where results proved the enhancement provided by the bolt anchorage. It avoided stress concentration in the tube and the sleeve, distributing it within the concrete, at the same time that enabled the full development of tensile bolt strength. A more detailed study, focused on bolt behaviour was undertaken by Pitrakkos and Tizani [14], who distinguished four mechanisms involved in Extended Hollo-bolt behaviour: internal bolt elongation, expanding sleeves, shank bond and anchorage.

Hence, the blind-bolt performance at room temperature has been studied by several researchers but there is still a gap in its understanding under fire conditions. In this respect, the European funded project COMPFIRE [15] has provided a helpful insight into the thermal behaviour of connections to partially encased composite columns and concrete filled tubular columns. This was preceded by the work of Ding and Wang [16, 17], who tested four different types of joints to CFST column in fire and one of them used a blind-bolt (the Molabolt). However, none of the previous researches studied deeply the effect of the blindbolt. On the other hand, it is noteworthy the discussion and contribution from Ding and Wang [17] to simplified temperature calculation methods of Eurocode 3 Part 1.2 (EC3) [18]

This paper deals with the thermal analysis of blind-bolts in endplate connections to HSS and CFST columns. Small-scale experiments and numerical models to obtain temperature distribution were conducted. The test program involved twelve specimens with a single blindbolt where variables were: section dimensions, Hollo-bolt or Extended Hollo-bolt, and HSS or CFST column. The aim of the work was to understand and evaluate the effect of these three variables. 
Pascual A M, Romero M L, Tizani W. Thermal behaviour of blind-bolted connections to hollow and concrete-filled steel tubular columns. Journal of constructional steel research 2015;107:137-149.

http://dx.doi.org/10.1016/j.jcsr.2015.01.014

Later on, the finite element models (FEM) of the tested specimens were carried out to simulate the heat transfer of the connections. An analysis of the thermal properties of materials and their interactions was accomplished by comparison with laboratory data. Numerical simulations were completed with models of the whole connection beam to column in order to verify the conclusions from the small-scale models.

Finally, the simplified methods of EC3 [18] and additional proposals developed by three researches were discussed. The suitability of these methods to calculate the temperature of blind-bolts in connection to HSS and CFST columns was evaluated by means of comparison with the experimental and numerical results.

Moreover, this work will provide valuable information for further thermo-mechanical calculations of these connections.

\section{EXPERIMENTAL TESTS OF THE THERMAL RESPONSE}

Due to the lack of experimental data about the thermal behaviour of blind-bolts, a test programme of twelve unloaded specimens (Table 1 and Fig. 2) was undertaken. For the sake of simplicity, samples with only one fastener were used. As it is shown in Fig. 3, they consisted of a blind-bolt (Hollo-bolt fastener system) that clamped a steel plate (equivalent to endplate) and a tubular section (a piece of HSS or CFST column).

\subsection{Specimens definition}

The experimental program was divided into four series of three specimens each, Fig. 2. Each series was tested on a different day and included specimens with the same column section dimensions (Table 1): the first specimen was a connection to a HSS column with a Hollo-bolt (termed UHB for Unfilled section with Hollo-bolt), the second one was a 
Pascual A M, Romero M L, Tizani W. Thermal behaviour of blind-bolted connections to hollow and concrete-filled steel tubular columns. Journal of constructional steel research 2015; 107:137-149.

http://dx.doi.org/10.1016/j.jcsr.2015.01.014

connection to a CFST column with a Hollo-bolt (termed HB), and in the last example an Extended Hollo-bolt was used (termed EHB).

Specimens of series 1 and 2 used square column, with dimensions $150 \times 150 \mathrm{~mm}$ and 220x220 mm, respectively. On the other hand, series 3 and 4 were rectangular with section tube of 250x150 mm and 350x150 mm, respectively. The clamped plate had a square section $110 \mathrm{~mm}$ long with a thickness of $15 \mathrm{~mm}$ for all the examples. The height of the piece of column was $285 \mathrm{~mm}$, which was previously proved to be large enough not to produce any interference in the isotherms distribution.

The concrete mixture had normal strength $\left(f_{c}=30 \mathrm{MPa}\right)$ with calcareous aggregates. Moisture content was measured by means of cubic specimens (150x150x150 mm), whose weight was taken before and after being in an oven at $150^{\circ} \mathrm{C}$ for 28 days. The value obtained for the moisture content was approximately $7 \%$ in concrete weight for all the mixtures.

The steel of tube columns was structural cold formed steel of grade S355, while the bolts utilised in the fastener system were high strength M16 (diameter of 16mm) grade 8.8, where the first digit is the value of ultimate strength $\left(f_{u}=800 \mathrm{MPa}\right)$ and the second one is the portion of ultimate strength that indicates the value of yield strength (i.e. $f_{y}=640 \mathrm{MPa}$ ). The shank length varied depending on the type of fastener used, $75 \mathrm{~mm}$ for the Hollo-bolt $(\mathrm{HB})$ and $120 \mathrm{~mm}$ for the Extended Hollo-bolt (EHB). Besides, EHB had a standard nut attached at the end of the bolt shank, Fig $1 b$.

The standard sleeve was used in all cases. Its specification is provided in the Lindapter catalogue [9]. Its length depends on the total thickness to fasten, in this case the $41.5 \mathrm{~mm}$ long was used with a strength of $430 \mathrm{MPa}$. 
Pascual A M, Romero M L, Tizani W. Thermal behaviour of blind-bolted connections to hollow and concrete-filled steel tubular columns. Journal of constructional steel research 2015;107:137-149.

http://dx.doi.org/10.1016/j.jcsr.2015.01.014

\subsection{Test setup and instrumentation}

Tests were performed in installations located at AIDICO (Instituto Tecnológico de la Construcción) in Valencia, Spain. A 5x3 m horizontal furnace was employed, equipped with 16 gas burners that reproduced the standard ISO834 [19] fire curve.

The three specimens of each series were tested at the same time. They were placed on bases made of heat-resistant concrete with the objective of being at mid-height of the furnace chamber, as it is shown in Fig. 4. Thick mineral wool was set in both ends of pieces to avoid the loss of heat through these surfaces.

Type $\mathrm{K}$ thermocouples were used to measure the evolution of temperatures at different points of the bolt and specimen, Fig. 5. Bolt temperature was obtained at least in three positions: the head of the bolt, the shank next to the tightened cone, and the end of shank inside the tubular section, indicated with number 1, 2 and 3, respectively. One more thermocouple was added in Extended Hollo-bolt fasteners, at an intermediate point of the shank length (EHB7). Positions 1 and 2 were the same for all the bolts, however position 3 varied with the length of the shank, so that, in the Extended Hollo-bolt it was located deeper inside the tube.

In concrete filled specimens, temperatures were monitored at 11 different locations. Not only the connection section (Section A-A') was controlled, but also a section $100 \mathrm{~mm}$ from it (Section B-B'), Fig. 5. The objective was to provide data for a detailed description of the temperature distribution within the cross section, and also along the piece.

\subsection{Experimental results}

Comparison between thermocouples measurements provided insight into the heat flow across the section and the effect of the three variables: tube section dimensions, concrete infill 
Pascual A M, Romero M L, Tizani W. Thermal behaviour of blind-bolted connections to hollow and concrete-filled steel tubular columns. Journal of constructional steel research 2015;107:137-149.

http://dx.doi.org/10.1016/j.jcsr.2015.01.014

and type of bolt. During the experiments the failure of some thermocouple protections was detected as an abrupt and unexpected change in the trend of temperature was registered. These measurements were not taken into account.

Temperature evolution during fire for specimen with $\mathrm{HB}$ of series 3 is depicted through Fig. 6. Thermocouples on the exposed surface reported similar values (HB1 HB4 and HB8) up to $30 \mathrm{~min}$, after which they started to separate registering a difference not higher than $50^{\circ} \mathrm{C}$ at 50 min. Temperatures in section A-A' and B-B' were approximately the same, as it was proved comparing values HB5 with HB10, HB6 with HB9, and HB7 with HB11. On the other hand, thermocouples in HB6 and HB9 reached higher temperatures than HB5, HB7, HB10 and HB11, because HB6 and HB9 were closer to the exposed surface. Meanwhile, temperatures of $\mathrm{HB} 5, \mathrm{HB} 7, \mathrm{HB} 10$ and $\mathrm{HB} 11$ were similar, as they were taken at nearly the same distance from the exposed surface, i.e. at the same isotherm. Equal field of temperatures was detected in the rest of specimens of series 1,2 and 4 .

Fig. 7 shows the increment of temperature in three locations of the shank (HB1, HB2, HB3) for a HB connection to a CFST column for the four tube section dimensions. Differences not higher than $50^{\circ} \mathrm{C}$ were observed between sections. This leads to the conclusion that temperature distribution in bolts was not affected by the range of dimensions of the tube sections analysed here. Nevertheless, further test program needs to include a wider range of section dimensions.

On the other hand, temperatures in connections to HSS were significantly different to the ones in connections to CFST columns. Fig. $8 \mathrm{a}$ and $8 \mathrm{~b}$ show the temperature in the bolt for specimens of series 1 and series 3 respectively. In unfilled sections, and after $30 \mathrm{~min}$ of fire exposure, the whole bolt presented approximately the same temperature (UHB1, UHB2, 
Pascual A M, Romero M L, Tizani W. Thermal behaviour of blind-bolted connections to hollow and concrete-filled steel tubular columns. Journal of constructional steel research 2015;107:137-149.

http://dx.doi.org/10.1016/j.jcsr.2015.01.014

UHB3). Nonetheless, some discrepancy was observed in the values taken for position 1 in unfilled pieces (HSS) exposed directly to fire. That could be atributted to nonhomogeneus heat distribution inside the furnace or to problems in thermocouples installation. Conversely, in connections to CFST, noteworthy differences between points 1,2 and 3 were observed. The temperature in the head of the bolt (HB1 and EHB1) after 30 minutes of fire exposure was $150^{\circ} \mathrm{C}$ higher than in position 2 (HB2 and EHB2), and around $400^{\circ} \mathrm{C}$ higher with respect to point 3 (HB3 and EHB3). Moreover, comparing temperatures at the three locations on the bolts between HSS and CFST connections, it was confirmed that concrete reduced drastically the temperature. For instance, after 30 min of exposure, bolt location UHB1 in the bolt head of HSS connection was aproximately $150^{\circ} \mathrm{C}$ hotter than $\mathrm{HB} 1$ or EHB1 in CFST connections, and $250^{\circ} \mathrm{C}$ in the case of temperatures at point 2.

The influence of a longer shank embedded in concrete was analysed by comparison of the two connections to CFST, with Hollo-bolt and Extended Hollo-bolt. No noticeable effects were detected in the temperatures at point 1 (HB1 and EHB1) and not even at point 2 (HB2 and EHB2). Same patterns were observed in the four sections.

Finally, it was concluded that in unfilled sections (HSS) temperatures increased faster and reached higher values than in filled sections (CFST). On the other hand, in connections to CFST, using Hollo-bolts or Extended Hollo-bolts did not produce any significant bolt temperature alteration except for position 3 .

In addition, some specimens were cut after the experiments to identify the bolt embedment within the concrete and the state of concrete mixture. In Fig. 9, it could be observed how concrete filled every gap between the parts of the fastener system, not leaving any empty space. Moreover, the clearance hole to accommodate the sleeve presented also 
Pascual A M, Romero M L, Tizani W. Thermal behaviour of blind-bolted connections to hollow and concrete-filled steel tubular columns. Journal of constructional steel research 2015;107:137-149.

http://dx.doi.org/10.1016/j.jcsr.2015.01.014

concrete mixture. Coloration in the concrete closer to the tube indicated the chemical changes produced in the hottest layers of infill.

\section{NUMERICAL SIMULATION OF TEST SPECIMENS}

\subsection{Description of the finite element model}

Thermal behaviour of tested pieces was simulated using the finite element analysis (FEA) package ABAQUS [20]. Three-dimensional numerical models were performed to represent the heat transfer problem. The three parts of connections were modelled: the hollow section, the steel plate and the blind-bolt, Fig. 10. Concrete infill was added as a fourth part in connections to CFST, Fig. 10d.

To model the fastener system, its geometry was simplified, reducing the number of elements to two: a main element which included shank, bolt head and fastener cone in the same solid; and the second one represented sleeve with legs in expanded state. The former changed in connections with Extended Hollo-bolt, where length of shank was larger and included a screwed nut attached at the end. Fig. 10c shows the parts corresponding with the blind-bolt of the FEM model. Avoiding complexity, the screw thread in bolt shank was not considered, nor the hexagonal shape of the bolt head and nut.

Despite the elements reduction, multiple interactions still existed between the several surfaces of different elements, therefore the FEM required detailed definitions of thermal contacts and their properties.

Three-dimensional eight-node heat transfer solid elements with thermal degree of freedom DC3D8 were used. A mesh sensitivity analysis was performed and finer elements 
Pascual A M, Romero M L, Tizani W. Thermal behaviour of blind-bolted connections to hollow and concrete-filled steel tubular columns. Journal of constructional steel research 2015;107:137-149.

http://dx.doi.org/10.1016/j.jcsr.2015.01.014

were used for bolts $(2-5 \mathrm{~mm})$ due to the size of the piece and to guarantee accuracy on the critical part. The size for the rest of the elements was not higher than $20 \mathrm{~mm}$.

\subsubsection{Thermal material properties}

\section{Concrete}

Temperature-variable thermal properties for concrete, specific heat and thermal conductivity, were taken from Eurocode 4 Part 1.2 (EC4) [21]. The moisture content is considered in the peak value of the specific heat at $115^{\circ} \mathrm{C}$. Recommendations give a peak value of $2020 \mathrm{~J} / \mathrm{kg} \mathrm{K}$ for a moisture content of $3 \%$ in concrete weight, and $5600 \mathrm{~J} / \mathrm{kg} \mathrm{K}$ for a moisture content of $10 \%$. A linear interpolation was used to calculate the peak for intermediate values. A moisture content of $7 \%$ in concrete weight was actually measured for the tested specimens.

\section{Steel}

The temperature dependent thermal properties for structural steel were extracted from EC3 [18], which are based on mild steel tests. Chemical composition and heat treatment in the fabrication of high strength steel mean different changes in the internal structure of the material under elevated temperatures. However, properties of normal strength steel have traditionally been used to characterise high strength bolts. In that respect, Kodur et al. [22] proposed new equations for thermal properties of steel bolts of grades A490 and A360.

The effect of considering mild steel properties in contrast with Kodur [22] expressions for high strength steel was analysed in section 3.2.1 of the present work. 
Pascual A M, Romero M L, Tizani W. Thermal behaviour of blind-bolted connections to hollow and concrete-filled steel tubular columns. Journal of constructional steel research 2015;107:137-149.

http://dx.doi.org/10.1016/j.jcsr.2015.01.014

\subsubsection{Thermal analysis}

A nonlinear thermal analysis was performed for each specimen. The thermal load was transferred to the exposed surfaces by convection and radiation mechanisms. Instead of applying the standard curve ISO834 [19], the temperature evolution registered in the furnace during experiments was used, in order not to add more discrepancies in the results, since they differed slightly.

The parameters that defined the heat transfer problem were adopted from Eurocode 1 Part 1.2 [23]:

- Coefficient of convective heat transfer at the exposed surface: $h=25 \mathrm{~W} / \mathrm{m}^{2} \mathrm{~K}$.

- Configuration factor for radiation at the exposed surface: $\phi=1$.

- Stephan-Boltzmann constant: $\sigma=5.67 \times 10^{-8} \mathrm{~W} / \mathrm{m}^{2} \mathrm{~K}^{4}$.

- Emissivity of the exposed surface: $\varepsilon_{\mathrm{f}}=0.7$.

- Emissivity of the fire: $\varepsilon_{\mathrm{f}}=1$.

- Initial temperature: $\mathrm{T}_{0}=20^{\circ} \mathrm{C}$.

On the other hand, the mechanism that governed the heating through each part of connection was conductivity, which depends on the thermal properties of the material. In the case of interactions between surfaces, heat transfer is produced by radiation and mainly conduction. For the latter mechanism a perfect contact could be assumed, which implies the same temperature for the points at boundaries. Nevertheless, thermal resistance was likely to appear and reduce the heat conduction, which is modelled by defining a gap conductance. Traditionally, authors have neglected this, but the influence on the temperature field is considerably important in many cases. 
Pascual A M, Romero M L, Tizani W. Thermal behaviour of blind-bolted connections to hollow and concrete-filled steel tubular columns. Journal of constructional steel research 2015;107:137-149.

http://dx.doi.org/10.1016/j.jcsr.2015.01.014

Gap conductance has been associated with gap clearance [24] or steel tube temperature [25] in the interface steel concrete of CFST columns. In the reported connections, not only the interface between steel tube and concrete core exists, but also several more contacts occurred due to the fastener system. A dependent definition of thermal resistance for each interaction is complex and would involve many factors at the same time. Therefore, based on the work of Espinos et al. [1], constant values of gap conductance were evaluated. Finally, perfect contact was deemed in all contacts, except for interactions sleeve with bolt shank and hole surfaces (plate and tube) and tube with concrete infill (Fig. 11), where a gap thermal conductance of $200 \mathrm{~W} / \mathrm{m}^{2} \mathrm{~K}$ was employed. A sensitivity study was conducted to reach these assumptions as it is described in section 3.2.2.

For the radiative heat transfer mechanism surface emissivity for both steel and concrete was 0.7 , and the configuration factor was 1 .

Results from the nonlinear thermal analysis were temperature curves obtained for each node of the three dimensional model.

\subsection{Validation of the numerical model}

The experimental data from the laboratory tests was used for the validation of the numerical calculation by means of comparison between temperatures obtained through the FEM and thermocouples measurements.

In Fig. 12a and $12 \mathrm{~b}$ the overall temperature-time response for the experimentally controlled locations of bolt is presented, specifically for specimens to CFST columns of series 3. For the three types of connections comprising the series a good correlation was observed between experiments and FEA calculations. The most noticeable differences were detected initially for location 1, which was on the exposed surface, probably caused by an uneven 
Pascual A M, Romero M L, Tizani W. Thermal behaviour of blind-bolted connections to hollow and concrete-filled steel tubular columns. Journal of constructional steel research 2015;107:137-149.

http://dx.doi.org/10.1016/j.jcsr.2015.01.014

distribution of heat in the furnace or inappropiate thermocouple installation. The same conclusions were obtained for the rest of the series.

In the following section the influence of the thermal properties on the response of high strength steel of bolts and the thermal resistance in the contacts is discussed, analysing the accuracy with test results.

\subsubsection{Thermal properties of high strength steel of bolts.}

\section{Steel}

Chemical composition and manufacturing process make high strength steel of bolts behave different to conventional mild steel, however, in the abscense of experimental data, the same thermal and mechanical properties were assumed for both. Carbon content affects the thermal properties of steel, a higher quantity of carbon reduces steel heat conductivity.

Several authors have dealt with the properties of mild steel or structural steel at elevated temperatures, and also with the mechanical properties of high strength steel in fire, but only Kodur et al. [22] included the temperature dependent definition of the thermal properties for high strength bolt steel. They carried out an experimental program to get an insight into the mechanical and thermal performance of A325 (yield strength $\mathrm{f}_{\mathrm{y}}=630 \mathrm{MPa}$ and ultimate strength $\left.\mathrm{f}_{\mathrm{u}}=830 \mathrm{MPa}\right)$ and $\mathrm{A} 490\left(\mathrm{f}_{\mathrm{y}}=895 \mathrm{MPa}\right.$ and $\left.\mathrm{f}_{\mathrm{u}}=1030 \mathrm{MPa}\right)$ at elevated temperatures. Conventional A36 steel $\left(\mathrm{f}_{\mathrm{y}}=290 \mathrm{MPa}\right.$ and $\left.\mathrm{f}_{\mathrm{u}}=500 \mathrm{MPa}\right)$ was also tested for comparison. Finally, laboratory data was used to formulate equations for specific heat and thermal conductivity. Samples were heated up to $735^{\circ} \mathrm{C}$, when the phase change occurs in steel. It was observed that higher level of carbon, as possessed by A429, reduced slightly the conductivity. Fig. 13 depicts the thermal properties established by Kodur [22] and EC3 [18] provisions. 
Pascual A M, Romero M L, Tizani W. Thermal behaviour of blind-bolted connections to hollow and concrete-filled steel tubular columns. Journal of constructional steel research 2015;107:137-149.

http://dx.doi.org/10.1016/j.jcsr.2015.01.014

In this research, the influence of modifications reported by Kodur et al. [22] was assessed through FEM simulations. Specimens of Series 2 were calculated considering both EC3 [18] and Kodur et al. [22] thermal properties for bolts M16 grade 8.8 (yield strength $\mathrm{f}_{\mathrm{y}}=640 \mathrm{MPa}$ and ultimate strength $\mathrm{f}_{\mathrm{u}}=800 \mathrm{MPa}$ ). Eventually, the slight differences in properties meant there was no significant influence on the connection temperatures.

\subsubsection{Gap thermal conductance}

A gap conductance coefficient was employed at the boundary of elements in contact to take into account the resistance to heat transfer conduction across the interactions. Model interactions were grouped in steel-steel and steel-concrete contacts in order to study its influence on temperature field.

\section{Steel-steel interactions}

Steel-steel interactions occurred between steel elements surfaces of the connection: bolt head to plate, sleeve to plate hole surface, sleeve to tube hole surface, sleeve to bolt shank, sleeve to bolt head and plate to tube column. First approach adopted null thermal resistance in all of them, but results overestimated bolt temperatures, Fig. 14a, that led to consider a gap conductance at some of the boundaries.

Actually, clearances appeared between some of these surfaces. Most perceptible voids were located between sleeve and hole surfaces, and also between sleeve and bolt shank. Concrete mixture filled the spaces, as could be observed in test specimens of Fig. 9. So, a gap conductance was finally adopted in sleeve to hole surfaces and sleeve to shank interactions. The recommended constant value $[1,24]$ of $200 \mathrm{~W} / \mathrm{m}^{2} \mathrm{~K}$ was evaluated, which gave proper results. 
Pascual A M, Romero M L, Tizani W. Thermal behaviour of blind-bolted connections to hollow and concrete-filled steel tubular columns. Journal of constructional steel research 2015;107:137-149.

http://dx.doi.org/10.1016/j.jcsr.2015.01.014

Fig. 14a shows the comparison between numerical values of temperatures considering perfect contact and thermal resistance, for HB connection to CFST of series 1, and also with experimental data. The inclusion of the indicated thermal resistance enhanced the FEM accuracy. Point 1 (HB1), directly exposed to fire, presented the same temperature with and without the thermal resistance. However, temperature at points 2 and 3 (HB2 and HB3) decreased in respect of the case of using perfect contact.

Different values of gap conductance were studied: 100 or $10 \mathrm{~W} / \mathrm{m}^{2} \mathrm{~K}$, but they did not substantially affect the results.

\section{Concrete-steel interactions}

Concrete-steel interactions included the contact between the steel tube column and concrete core, and the contacts of the embedded part of fastener system with concrete mixture around it.

An initial approach assumed a value of $200 \mathrm{~W} / \mathrm{m}^{2} \mathrm{~K}$, following the guidance of $[1,24]$ for all the interactions steel to concrete without distinction. The higher dilatation of steel involved the separation between the steel tube and concrete infill during fire, as a consequence, a gap thermal conductance appeared. Nevertheless, in the area of embedded bolt, dilatation of steel was limited by the concrete, so separation between concrete infill and steel bolt surfaces resulted consistently difficult to materialize. Therefore, a second approach considered the elimination of the gap at fastener boundaries. Comparison between both approaches and tests is presented in Fig. 14b, for HB connection of series 1. The effect of considering perfect contact at boundaries of the blind-bolt with concrete reduced the temperature at points 2 and 3, and enhanced the correlation with the experiments. 
Pascual A M, Romero M L, Tizani W. Thermal behaviour of blind-bolted connections to hollow and concrete-filled steel tubular columns. Journal of constructional steel research 2015;107:137-149.

http://dx.doi.org/10.1016/j.jcsr.2015.01.014

\section{NUMERICAL MODEL OF THE WHOLE CONNECTION}

Real bolted endplate connections between an I-beam and a CFST column were not tested in this research, but small-scale connections were tested instead. Validation of the FEM simulation with the test specimens justified the appropriateness of assumptions considered and their application to develop a numerical model of the whole bolted connection. Therefore, with the aim of extending the insight into the thermal behaviour of a single blind-bolt in a connection to HSS and CFST column, an entire representation of a complete joint was accomplished by means of FEMs, Fig. 15.

The simulated connection was mainly composed of five different parts as it is presented in Fig. 16:

- a hollow square steel section column with the same size as the specimens of series 2, i.e. $220 \mathrm{~mm}$ in side length and $10 \mathrm{~mm}$ in thickness,

- a standard I-shape section steel beam named IPE180,

- four Hollo-bolt fasteners M16 grade 8.8, in two rows separated $100 \mathrm{~mm}$ in height.

- a rectangular steel plate with dimensions 200x130x15 mm,

- a concrete slab on the beam, representing real conditions of a building frame,

- concrete infill inside the tube column in connections to CFST.

In order to reduce computational cost and due to symmetry of geometry and thermal load, only half of the connection was modelled. The same thermal material properties and scheme for the heat transfer as in the small scale examples were applied. Fire development was assumed in the storey below, so the exposed areas were all the external surfaces of the elements except for the upper flange of beam, the concrete slab and the part of column over the concrete slab. The thickness of the concrete slab is not relevant in this study and only its 
Pascual A M, Romero M L, Tizani W. Thermal behaviour of blind-bolted connections to hollow and concrete-filled steel tubular columns. Journal of constructional steel research 2015; 107:137-149.

http://dx.doi.org/10.1016/j.jcsr.2015.01.014

effect as heat sink and storey separator was taken into account. Nonetheless, to prove the lack of slab thickness influence, the bolt temperature for slabs 20 and $60 \mathrm{~mm}$ thick was compared, detecting negligible differences.

\subsubsection{Results and discussion}

The overall temperature-time response for the three locations of the blind-bolts was obtained, but only results at 30 min will be analysed here due to the similar behaviour patterns detected along fire exposure.

Fig. 17 compares bolt temperature in the two rows from the endplate connection with values calculated numerically and experimentally in the small-scale specimens, for the same connection (HB connections of series 2).

Fig. 17a shows results for the I-beam connection to HSS column. Values calculated in the reduced numerical model fit accurately the temperature of the bottom row bolts, located closer to the bottom flange of the beam. Conversely, bolt temperatures in the upper row registered $100^{\circ} \mathrm{C}$ less than in the case of the simple FEM model, due to the influence of concrete slab effect, which was not included in the small-scale models.

Similar patterns of behaviour were detected in the cases of connection to CFST column Fig. 17b. The simple model, with one blind-bolt, achieved better correlation with the bolts in the lower row, which were less affected by the concrete slab effect. In addition, the most embedded section of the bolt (position 3) was less influenced by concrete slab, and consequently negligible differences appeared between the simple model and the model of the whole connection.

In conclusion, bolts in the complete endplate connection registered similar temperature distribution as in the small-scale models. Therefore, these simple models provided a good 
Pascual A M, Romero M L, Tizani W. Thermal behaviour of blind-bolted connections to hollow and concrete-filled steel tubular columns. Journal of constructional steel research 2015;107:137-149.

http://dx.doi.org/10.1016/j.jcsr.2015.01.014

approach to representing the thermal behaviour of the blind-bolt in the connection. Moreover, they made a safe prediction in the case of bolts closer to the concrete slab.

\section{EVALUATION OF EC3 PART 1.2 ANNEX D APPROACH}

Performance of advanced numerical models to calculate the temperature in connections is not always practical, thus literature review was accomplished to seek other simple methods. However, no simple analytical expressions were found suitable for connections to HSS and CFST, which has not helped the spread of the use of these connections.

This review included the study of Eurocode provisions relating to joints at elevated temperatures. EC4 [21] gives some requirements that specific connections should comply with to provide adequate fire resistance, but temperature distribution was not dealt with. On the other hand, EC3 in Clause D3 of Annex D [18] includes a simple method based on the behaviour of steelworks, which calculates the temperature in connections where beam supports a concrete slab. Suitability of this method is evaluated in the following section for HSS and CFST connection, using FEM of the whole endplate connection for comparison.

\subsection{Simple method of EC3 Part 1.2 Annex D. Application}

The method consists of equations (1) and (2) that determine the temperature $\theta_{\mathrm{h}}$ in a certain depth of the connection $h$ (Fig. 16) as a proportion of the beam bottom flange temperature oat midspan $\theta_{\mathrm{o}}$. The method can be applied to beam to column and beam to beam connections. The selection of which equation to use, depends on the height of the beam, D.

$$
\begin{aligned}
& \mathrm{D} \leq 400 \quad \theta_{h}=0,88 \theta_{o}[1-0,3(h / D)] \\
& \mathrm{D}>400
\end{aligned}
$$


Pascual A M, Romero M L, Tizani W. Thermal behaviour of blind-bolted connections to hollow and concrete-filled steel tubular columns. Journal of constructional steel research 2015; 107:137-149.

http://dx.doi.org/10.1016/j.jcsr.2015.01.014

$$
\begin{array}{ll}
\mathrm{h} \leq \mathrm{D} / 2 & \theta_{h}=0,88 \theta_{o} \\
\mathrm{~h}>\mathrm{D} / 2 & \theta_{h}=0,88 \theta_{o}[1-0,2(1-2 h / D)]
\end{array}
$$

Equation (1) was employed to estimate the temperature in an exterior point of the connections presented in the previous section, between a steel I-beam IPE180 and a square tube column 220x220 mm. Both, HSS and CFST columns were considered.

Before the application of the thermal gradient, it is necessary to determine temperature in the exposed bottom flange of the beam $\theta_{\mathrm{o}}$. For this purpose, and basing the whole calculation on analytical formulation of Eurocodes, equation (3) included in EC3 Clause 4.2.5.1 [18], was utilised.

$$
\Delta \theta_{a, t}=k_{s h} \frac{A_{m} / V}{c_{a} \rho_{a}} \dot{h}_{n e t} \Delta t
$$

This expression calculates a uniform value of temperature for an unprotected steel section exposed to fire by means of increments of time $\Delta t$. Flux of heat $h_{\text {net }}$ is divided by $c_{a} \rho_{a}$ ,that are the specific heat and the unit mass of steel, respectively. The ratio $A_{m} / V$ section factor indicated the relation of exposed area $A_{m}$ of the element per unit of length divided by $V$ volume of the element per unit of length in steel sections. Finally, $\mathrm{k}_{\mathrm{sh}}$ is the correction factor for the shadow effect, the value of which was calculated following the recommendations of EC3 [18].

Before obtaining temperature distribution along connections, accuracy of beam temperature extracted with EC3 Clause 4.2.5.1 [18] was verified against values from the FEM model, comparing temperature-time curves. Due to the similarity of results and to avoid confusion, these were not included in Fig. 18. 
Pascual A M, Romero M L, Tizani W. Thermal behaviour of blind-bolted connections to hollow and concrete-filled steel tubular columns. Journal of constructional steel research 2015; 107:137-149.

http://dx.doi.org/10.1016/j.jcsr.2015.01.014

\subsection{Results and discussion}

Temperatures at two depths of the connection, corresponding with the axis of the two bolt rows presented in Fig. 16 were studied: the head of blind-bolts in the upper row located at $0.75 \mathrm{D}$ from the beam bottom flange, and the ones in the lower row, at $0.25 \mathrm{D}$.

Fig. 18a presents equation results for connections to HSS. In comparison with FEM calculations, equation (1) of Annex D [18] was conservative up to approximately 20 min of fire exposure for bolts in the top row, and $23 \mathrm{~min}$ for bolts in the bottom row.

Moreover, temperature of HSS column was calculated using equation (3), aiming to know whether that value could be directly used to approach the temperature of bolts. In connections to HSS, the temperature of the tube column represented a safe estimation for the bolt in the bottom row, except for the first 10 minutes of exposure. In the case of blind-bolts in the top row, the use of tube column values implied that bolt temperature was overestimated by $150^{\circ} \mathrm{C}$ after $30 \mathrm{~min}$ of exposure. Fig. 18a also shows a good correlation between analytically and numerically time-temperature curve for the column.

Fig. 18b depicted results for connections to CFST. EC3 [18] predictions were safe up to 30 min for the top row bolts and 34 min for the bottom row bolts, which meant 10 min more of fire exposure than in the case of the HSS column.

Equation (3) is not applicable for calculating temperature in CFST section and a discussion about this is developed in the next section. Fig. $18 \mathrm{~b}$ includes the time-temperature curve for the steel tube of the CFST only from the FEM model. Temperatures of the tube column and blind-bolt from simulations showed slight differences between them. Bolts in the bottom row were $20-30{ }^{\circ} \mathrm{C}$ hotter than in the tube column because the concrete infill influence 
Pascual A M, Romero M L, Tizani W. Thermal behaviour of blind-bolted connections to hollow and concrete-filled steel tubular columns. Journal of constructional steel research 2015;107:137-149.

http://dx.doi.org/10.1016/j.jcsr.2015.01.014

was less important. Conversely, temperature in upper bolts was $30-50{ }^{\circ} \mathrm{C}$ lower than temperature column.

In conclusion, equation of Annex D [18] provides a rough approximation of blind-bolt temperatures in HSS and CFST connections. Although for CFST connections gave safe values up to $30 \mathrm{~min}$ of fire exposure, it is not able its use as a feasible tool to determine the temperature in the bolts.

\section{DISCUSSION ABOUT OTHER DESIGN RECOMMENDATIONS}

Application of other alternative methods to calculate the temperature in the exposed head of blind-bolts in connections to CFST is presented here. Firstly, the previously introduced equation of EC3 in clause 4.2.5.1 [18] is analysed, together with its modifications by Ding and Wang [17]. Thereafter, proposals of Espinos et al. [26] and Leskela [27] are evaluated.

\subsection{Simple calculation method of EC3 Part1.2}

The use of equation (3), included in section 5.1 of the present report, required the definition of the factor $\mathrm{A}_{\mathrm{m}} / \mathrm{V}$. Table 4.2 of EC3 [18] contains some expressions to calculate this factor, but always for steelworks. Therefore, equation (3) cannot be applied for a composite steel and concrete section unless the column is deemed either as a hollow section, disregarding the effect of concrete (termed as HSS), or as solid steel section (termed as CFST). Table 2 includes the values of $\mathrm{A}_{\mathrm{m}} / \mathrm{V}$ under these two hypotheses.

EC3 [18] simple method was employed by Ding and Wang [17] to calculate the temperatures in connections to CFST columns. They developed several expressions to obtain the section ratio $A_{m} / V$, which depended on the part of the joint and the type of assembly. 
Pascual A M, Romero M L, Tizani W. Thermal behaviour of blind-bolted connections to hollow and concrete-filled steel tubular columns. Journal of constructional steel research 2015; 107:137-149.

http://dx.doi.org/10.1016/j.jcsr.2015.01.014

Table 2 presents the section factors for endplate bolted connections. The section factor 1 only considered the endplate being heated from one side and used the thickness of the endplate (t1). The factor 2 assumed that the combined endplate (t1) and tube thickness (t2) was heated from one side. Finally, the factor 3 considered the heating corner and used the thickness (t1) and width of the endplate (11), and the thickness (t2) and width of the tube (12).

\subsection{Equivalent temperature by Espinos, and Leskela}

Espinos et al. [26] and Leskela [27] worked on obtaining an equivalent temperature for steel and concrete in CFST. Their aim was to create a simple method that provided a uniform value of temperature for each material of the section, so that, it did not represent a problem to determine design capacity of the composite element.

The formula proposed by Espinos et al. [26] for the equivalent temperature of steel was applicable for any fire resistance time. Although it was obtained for circular sections, here it will be assessed for square and rectangular sections. The value of temperature depended on the ratio $A_{m} / V$ and the time $\mathrm{R}$.

$$
\theta_{a, e q}=342.1+10.77 R-0.044 R^{2}+3.922 A_{m} / V-0.025 R \cdot A_{m} / V
$$

Leskela [27] provided two tables with equations for circular and rectangular CFST. Those estimated the steel temperature for different time resistance periods as a function of diameter and side length (b). For a fire exposure of $30 \mathrm{~min}$, the temperature in the square section is given by the following equation:

$$
\theta_{a, e q}=650+45 \cdot \sqrt{\frac{400-b}{280}} \quad 120 \leq b \leq 400
$$


Pascual A M, Romero M L, Tizani W. Thermal behaviour of blind-bolted connections to hollow and concrete-filled steel tubular columns. Journal of constructional steel research 2015; 107:137-149.

http://dx.doi.org/10.1016/j.jcsr.2015.01.014

\subsection{Results and discussion}

The suitability of these methods to calculate the external temperature of the blind-bolt was checked by comparison with temperatures measured in laboratory for position 1 of blindbolts. Provided that the type of bolt, Hollo-bolt or Extended Hollo-bolt, did not influence that temperature, only the first type of fastener was considered. The fire exposure time used as a reference was 30 min and the four different tube section dimensions were taken into account.

Equation (3) was evaluated assuming 5 different section ratios $A_{m} / V$ for the connection section: as a hollow section (EC3-HSS), as a solid section of steel (EC3-CFST), and the three proposals from Ding and Wang [17].

The section factor for the hollow section generated the highest temperature, around $150^{\circ} \mathrm{C}$ more than in the tests, Fig. 19. Nonetheless, the adjustment was better than the one assuming a steel solid section, which underestimated the temperature by $300^{\circ} \mathrm{C}$.

For the connections studied by Ding and Wang [17], factor 3 (Table 2) was the most suitable one. Conversely, for the examples presented in this research, factor 1 (EC3-F1 WANG) achieved the better approximation, whose difference with tests was not higher than $30^{\circ} \mathrm{C}$, Fig. 19. In the case of section $220 \times 220 \mathrm{~mm}$, the same accuracy was obtained with factor 1 and 3 (EC3-F3 WANG). For the rest of sections, factor 3 miscalculated the temperature in $100^{\circ} \mathrm{C}$ less. In all cases, factor 2 (EC3-F2 WANG) provided temperatures around $150^{\circ} \mathrm{C}$ lower than the measured ones.

In conclusion, factor 1 estimated values of temperature higher than factors 2 and 3 so that it was the most suitable ratio for thicker sections, where concrete effect is smaller and bolts reached higher temperature. But, there were exceptions associated with the width of the column and of endplate: when the endplate width (11) was considerably smaller than the tube 
Pascual A M, Romero M L, Tizani W. Thermal behaviour of blind-bolted connections to hollow and concrete-filled steel tubular columns. Journal of constructional steel research 2015;107:137-149.

http://dx.doi.org/10.1016/j.jcsr.2015.01.014

side length (12), factor 3 achieved also good adjustment, as it was pointed out for the column with dimensions $220 \times 220 \mathrm{~mm}$ (series 2).

Fig. 19 shows that temperatures calculated using the equations proposed by Espinos et al. [26] and Leskela [27]. Both presented similar results and overestimated the temperature in the exposed part of bolts, $100^{\circ} \mathrm{C}$ for the square sections $150 \times 150 \mathrm{~mm}$ (series 1 ) and $80^{\circ} \mathrm{C}$ for the rest.

\section{SUMMARY AND CONCLUSIONS}

This research provides insight into the effect of different aspects that are involved in the thermal behaviour of blind-bolt connections.

First, the paper deals with the experimental and numerical thermal study of small-scale connections to HSS and CFST with Hollo-bolt and Extended Hollo-bolt. An experimental program comprising 12 specimens was carried out, where thermal response was monitored throughout the fire. Variables considered were: section dimensions of the tube column (150x150, 220x220, 250x150, 350x150 mm), type of fastener system (Hollo-bolt or Extended Hollo-bolt), and type of connection (to HSS or CFST). Slight influence of section dimensions was detected between the four different sizes studied, less than $30^{\circ} \mathrm{C}$ differences throughout the entire period of fire exposure. Conversely, the effect of concrete filling the steel section tube was noticeable, even in the exposed position of blind-bolts, where $100^{\circ} \mathrm{C}$ lower temperatures were measured in CFST than in HSS connections. Regarding the type of blindbolt, the longer shank embedded in concrete of Extended Hollo-bolt presented a negligible effect on the external and more damaged part of the bolt. 
Pascual A M, Romero M L, Tizani W. Thermal behaviour of blind-bolted connections to hollow and concrete-filled steel tubular columns. Journal of constructional steel research 2015;107:137-149.

http://dx.doi.org/10.1016/j.jcsr.2015.01.014

Afterwards, FEM of tested specimens were carried out. They simulated with acceptable accuracy the heat transfer behaviour occurred in the experiments. The main aspects calibrated in the model were thermal properties of high strength steel bolt and thermal resistance to heat flow through the contacts. It was concluded that the use of thermal properties of mild steel for high strength steel bolts represented a good approximation, as well as the recommendation of employing a gap conductance of $200 \mathrm{~W} / \mathrm{m}^{2} \mathrm{~K}$ for the sleeve interaction with the hole surfaces and the steel tube with the concrete core.

Secondly, the FEA work included a model of whole endplate connections between an IPE180 beam and a HSS and a CFST column. In addition to the fuller understanding of the thermal behaviour of the whole connection, the purpose was also to justify the use of smallscale connections to study the connections behaviour at elevated temperatures. Similar and safe predictions resulted from the FEM simulations of small-scale specimens.

Finally, the suitability of some non-specific simple analytical methods to obtain the bolt temperatures in the connections was studied. On the one hand, thermal gradient from Annex D of EC3 [18] was deemed a poor approximation, safe up to $20 \mathrm{~min}$ and $30 \mathrm{~min}$ of fire exposure for connections to HSS and CFST, respectively. On the other hand, the equation of EC3 Clause 4.2.5.1 [18], function of ratio $\mathrm{A}_{\mathrm{m}} / \mathrm{V}$, was found not appropriate to be used in CFST column connections except for the case of using ratios $A_{m} / V$ (factor 1) proposed by Ding and Wang [17], which gave more realistic approaches. However, their application should be carefully considered depending on the elements involved in the connections. Lastly, it was observed that equations of Espinos et al. [26] and Leskela [27], to calculate equivalent temperature in CFST connections, overestimated the temperature in the connections by around $100^{\circ} \mathrm{C}$. 
Pascual A M, Romero M L, Tizani W. Thermal behaviour of blind-bolted connections to hollow and concrete-filled steel tubular columns. Journal of constructional steel research 2015;107:137-149.

http://dx.doi.org/10.1016/j.jcsr.2015.01.014

In conclusion, the present research includes valuable experimental and numerical data useful to understand the thermal performance of blind-bolt connections and necessary for its further thermo-mechanical analysis. Nevertheless, additional work is required to extend the range of parameters and provide simple expressions for bolt temperatures in HSS and CFST connections.

\section{ACKNOWLEDGEMENTS}

The authors would like to express their sincere gratitude to the Spanish "Ministerio de Ciencia e Innovación" for the help provided through the Project BIA2012-33144 and the research scholarship BES-2010-035022.

Acknowledge is expressed to Lindapter International ${ }^{\circledR}$ for providing the fastener systems to carry out the experiments.

\section{REFERENCES}

[1] Espinos A, Romero ML, Hospitaler A. Advanced model for predicting the fire response of concrete filled tubular columns. Journal of Constructional Steel Research 2010. 66(8-9): 1030-1046.

[2] National Institute of Standards and Techology (NIST). Final Report on the collapse of the World Trade Center towers. USA: National Institute of Standards and Technology. 2005.

[3] National Institute of Standards and Techology (NIST). Final Report on the collapse of the World Trade Center building 7. USA: National Institute of Standards and Technology. 2008. 
Pascual A M, Romero M L, Tizani W. Thermal behaviour of blind-bolted connections to hollow and concrete-filled steel tubular columns. Journal of constructional steel research 2015;107:137-149.

http://dx.doi.org/10.1016/j.jcsr.2015.01.014

[4] Al-Jabri KS, Burgess IW, Lennon T, Plank RJ. Moment-rotation-temperature curves for semi-rigid joints. Journal of Constructional Steel Research 2005. 61(3): 281-303.

[5] Al-Jabri KS, Seibi A, Karrech A. Modelling of unstiffened flush end-plate bolted connections in fire. Journal of Constructional Steel Research 2006. 62(1-2): 151-159.

[6] Wang YC, Dai XH, Bailey CG. An experimental study of relative structural fire behaviour and robustness of different types of steel joint in restrained steel frames. Journal of Constructional Steel Research 2011. 67(7): 1149-1163.

[7] Dai XH, Wang YC, Bailey CG. Numerical modelling of structural fire behaviour of restrained steel beam-column assemblies using typical joint types. Engineering Structures 2010. 32(8): 2337-2351.

[8] Tizani W, Al-Mughairi A, Owen JS, Pitrakkos T. Rotational stiffness of a blind-bolted connection to concrete-filled tubes using modified Hollo-bolt. Journal of Constructional Steel Research 2013. 80(0): 317-331.

[9] Lindapter. Type HB - Hollo-Bolt. Cavity fixings 2,product brochure. Lindapter International, UK. 2012: p 41-3.

[10] Elghazouli AY, Málaga-Chuquitaype C, Castro JM, Orton AH. Experimental monotonic and cyclic behaviour of blind-bolted angle connections. Engineering Structures 2009. 31(11): 2540-2553.

[11] Liu Y, Málaga-Chuquitaype C, Elghazouli AY. Response and component characterisation of semi-rigid connections to tubular columns under axial loads. Engineering Structures 2012. 41(0): 510-532.

[12] Liu Y, Málaga-Chuquitaype C, Elghazouli AY. Behaviour of beam-to-tubular column angle connections under shear loads. Engineering Structures 2012. 42(0): 434-456. 
Pascual A M, Romero M L, Tizani W. Thermal behaviour of blind-bolted connections to hollow and concrete-filled steel tubular columns. Journal of constructional steel research 2015;107:137-149.

http://dx.doi.org/10.1016/j.jcsr.2015.01.014

[13] Wang ZY, Tizani W, Wang QY. Strength and initial stiffness of a blind-bolt connection based on the T-stub model. Engineering Structures 2010. 32(9): 25052517

[14] Pitrakkos T, Tizani W. Experimental behaviour of a novel anchored blind-bolt in tension. Engineering Structures 2013. 49(0): 905-919.

[15] Research Fund for Coal and Steel (RFCS). Design of composite joints for improved fire robustness, Final Report. Belgium: European Commission 2014.

[16] Ding J, Wang YC. Experimental study of structural fire behaviour of steel beam to concrete filled tubular column assemblies with different types of joints. Engineering Structures 2007. 29(12): 3485-3502.

[17] Ding J, Wang YC. Temperatures in unprotected joints between steel beams and concrete-filled tubular columns in fire. Fire Safety Journal 2009. 44(1): 16-32.

[18] CEN. EN 1993-1-2, Eurocode 3: Design of steel structures. Part 1-2: General rules Structural fire design. Brussels, Belgium: Comité Européen de Normalisation. 2005.

[19] ISO 834: Fire resistance tests, elements of building construction. Switzerland: International Standards Organisation. 1980.

[20] Pawtucket RIH, Karlsson \& Sorenson, Inc. ABAQUS. ABAQUS/Standard Version 6.6 User's Manual: Volumes I-III.

[21] CEN. EN 1994-1-2, Eurocode 4: Design of composite steel and concrete structures. Part 1-2: General rules - Structural fire design. Brussels, Belgium: Comité Européen de Normalisation. 2005. 
Pascual A M, Romero M L, Tizani W. Thermal behaviour of blind-bolted connections to hollow and concrete-filled steel tubular columns. Journal of constructional steel research 2015;107:137-149.

http://dx.doi.org/10.1016/j.jcsr.2015.01.014

[22] Kodur V, Kand S, Khaliq W. Effect of Temperature on Thermal and Mechanical Properties of Steel Bolts. Journal of Materials in Civil Engineering 2012. 24(6): 765774.

[23] CEN. EN 1991-1-2, Eurocode 1: Actions on structures. Part 1-2: General actions Actions on structures exposed to fire. Brussels, Belgium: Comité Européen de Normalisation. 2002.

[24] Ding J, Wang YC. Realistic modelling of thermal and structural behaviour of unprotected concrete filled tubular columns in fire. Journal of Constructional Steel Research 2008. 64(10): 1086-1102.

[25] Ghojel J. Experimental and analytical technique for estimating interface thermal conductance in composite structural elements under simulated fire conditions. Experimental Thermal and Fluid Science 2004. 28(4): 347-354.

[26] Espinos A, Romero ML, Hospitaler A. Simple calculation model for evaluating the fire resistance of unreinforced concrete filled tubular columns. Engineering Structures 2012. 42: 231-244.

[27] Leskela MV. Background Document II: Charateristics for a simple calculation method/New Annex H/EN 1994-1-2 (C). Draft 16.01.2013. 2013. 
Pascual A M, Romero M L, Tizani W. Thermal behaviour of blind-bolted connections to hollow and concrete-filled steel tubular columns. Journal of constructional steel research 2015;107:137-149.

http://dx.doi.org/10.1016/j.jcsr.2015.01.014

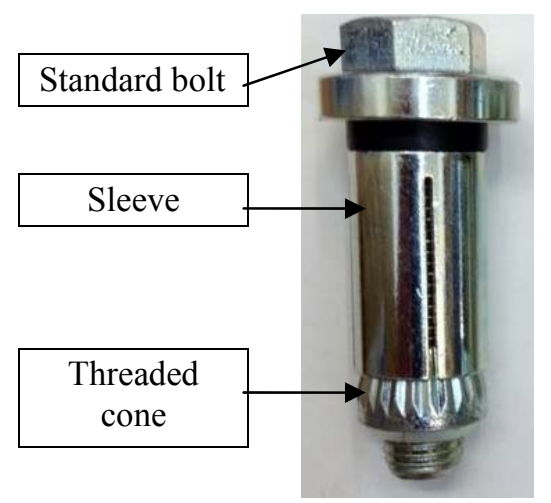

a)

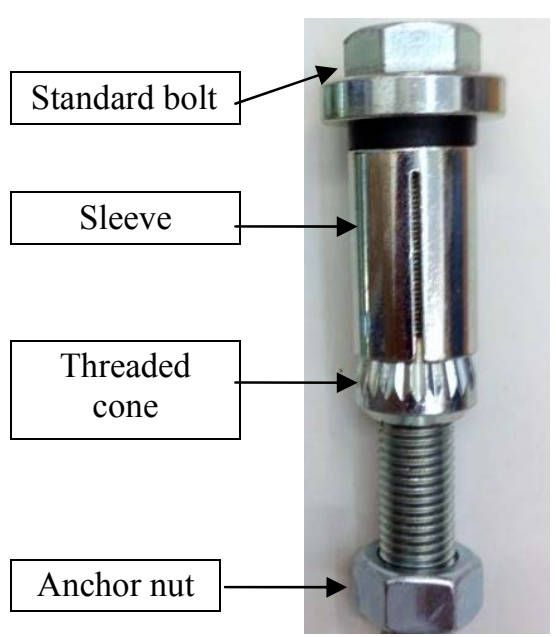

b)

Fig. 1. Blind-bolts: a) Hollo-bolt type, b) Extended Hollo-bolt type. 
Pascual A M, Romero M L, Tizani W. Thermal behaviour of blind-bolted connections to hollow and concrete-filled steel tubular columns. Journal of constructional steel research 2015;107:137-149.

http://dx.doi.org/10.1016/j.jcsr.2015.01.014

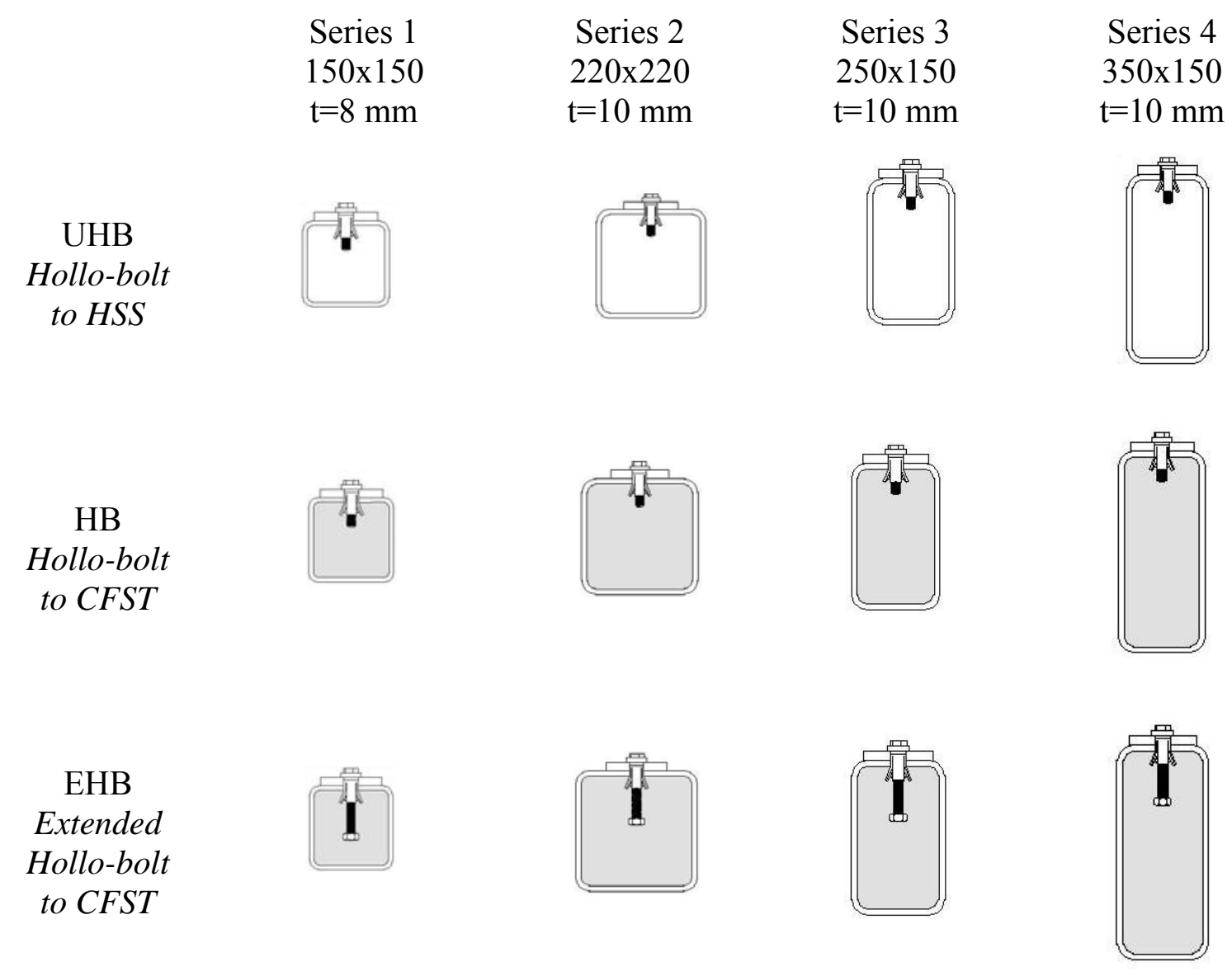

Fig. 2. Test specimens.

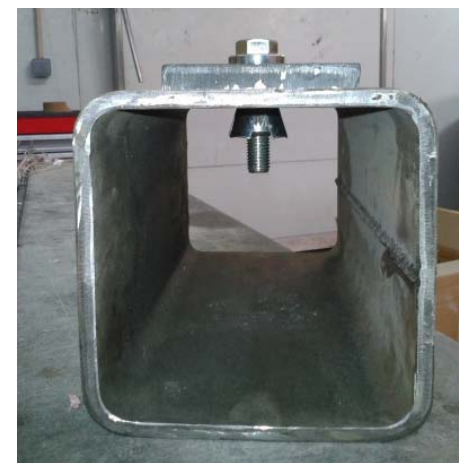

a)

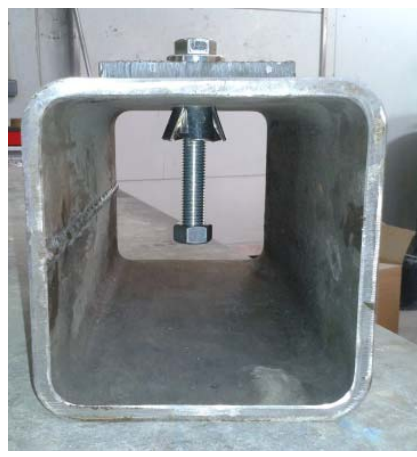

b)

Fig. 3. Test specimens before pouring concrete: a) Hollo-bolt, b) Extended Hollo-bolt. 
Pascual A M, Romero M L, Tizani W. Thermal behaviour of blind-bolted connections to hollow and concrete-filled steel tubular columns. Journal of constructional steel research 2015;107:137-149.

http://dx.doi.org/10.1016/j.jcsr.2015.01.014

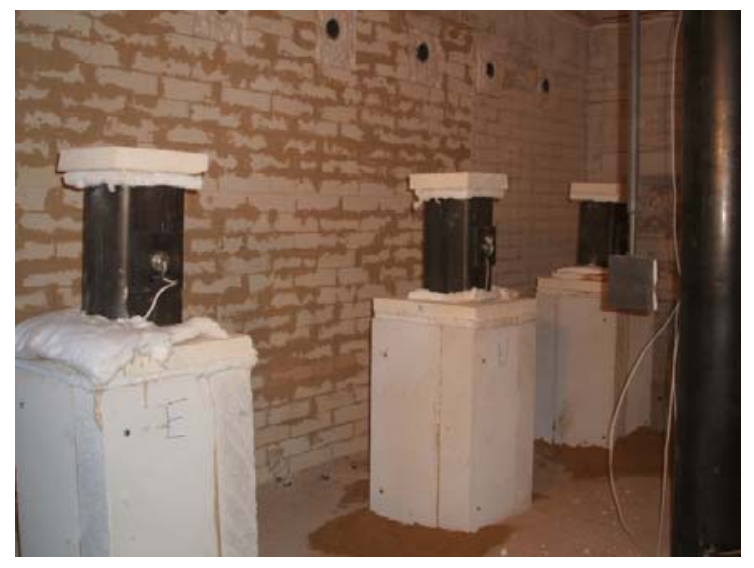

Fig. 4. Location of test specimens in furnace. 
Pascual A M, Romero M L, Tizani W. Thermal behaviour of blind-bolted connections to hollow and concrete-filled steel tubular columns. Journal of constructional steel research 2015; 107:137-149.

http://dx.doi.org/10.1016/j.jcsr.2015.01.014

\section{Section A-A'}
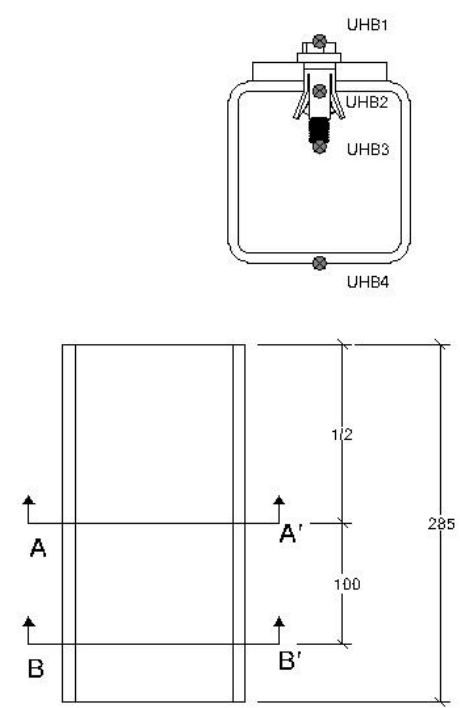

Section A-A'

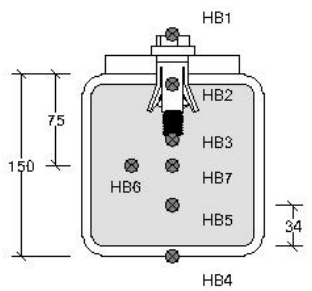

Section B-B'

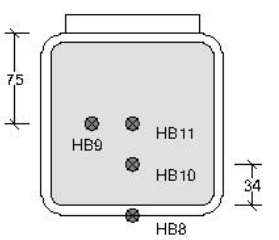

Section A-A'

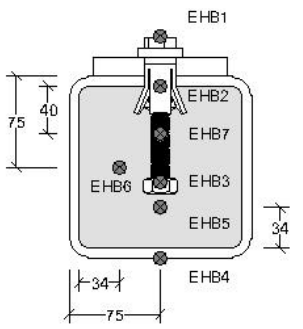

Section B-B'

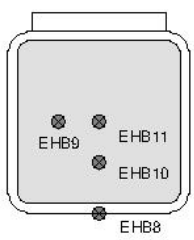

Fig. 5. Thermocouples position in specimens of series 1 .
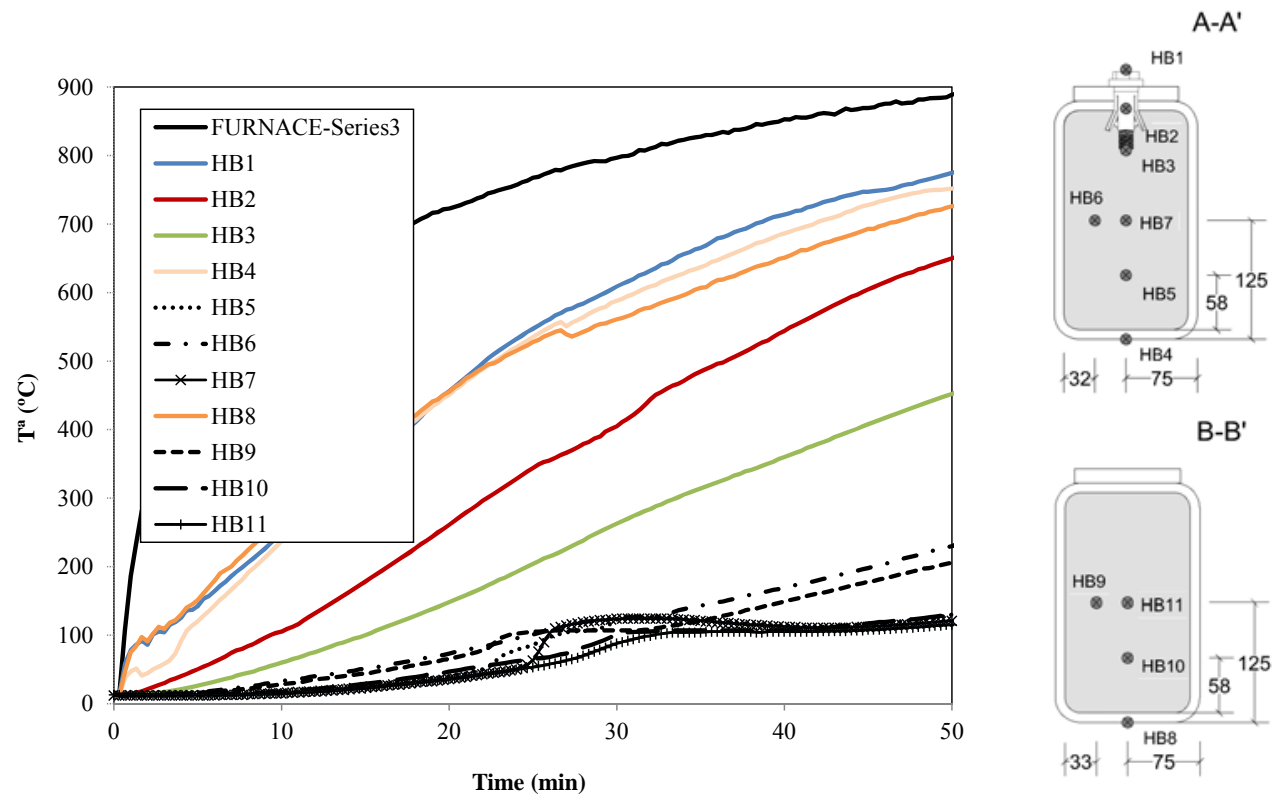

Fig. 6. Time-temperature response measured by thermocouples in CFST connection with HB of series 3 . 
Pascual A M, Romero M L, Tizani W. Thermal behaviour of blind-bolted connections to hollow and concrete-filled steel tubular columns. Journal of constructional steel research 2015;107:137-149.

http://dx.doi.org/10.1016/j.jcsr.2015.01.014
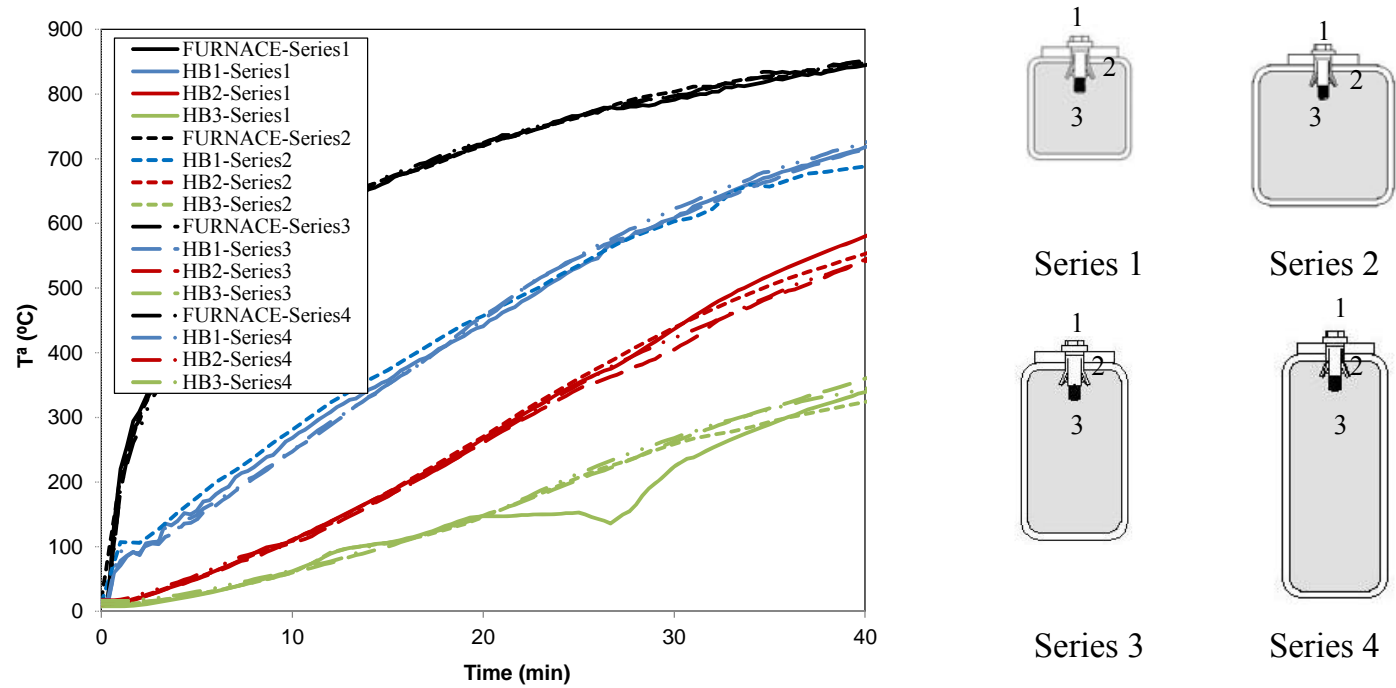

Series 1

Series 2
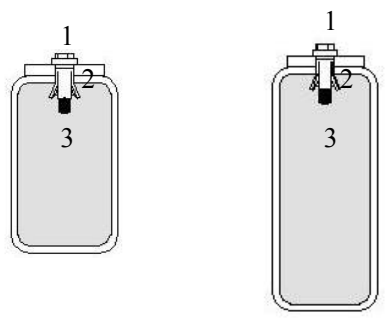

Series 3

Series 4

Fig. 7. Comparison of bolt temperature between different steel sections in test specimens of HB to CFST connections. 
Pascual A M, Romero M L, Tizani W. Thermal behaviour of blind-bolted connections to hollow and concrete-filled steel tubular columns. Journal of constructional steel research 2015;107:137-149.

http://dx.doi.org/10.1016/j.jcsr.2015.01.014
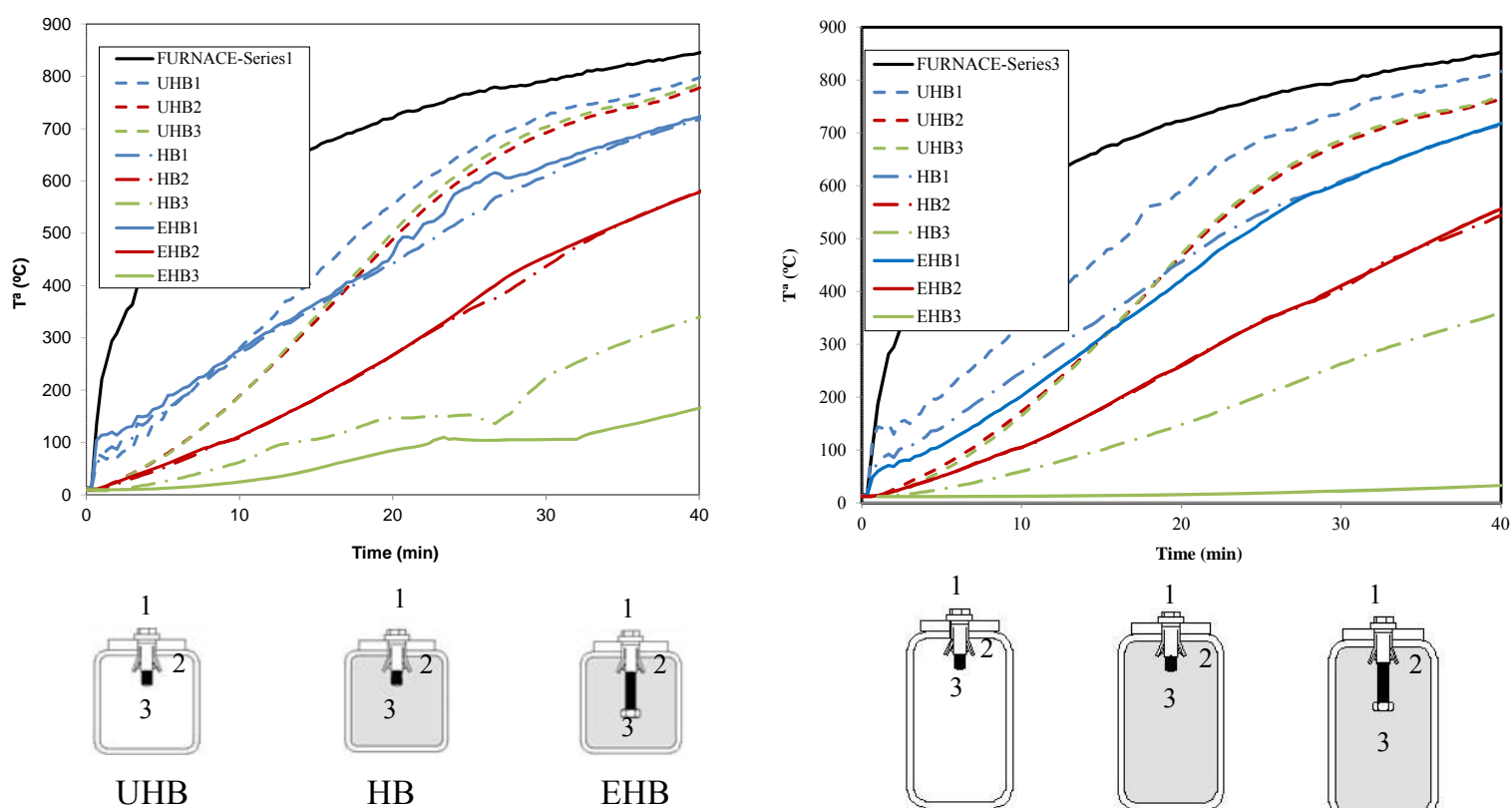

a)

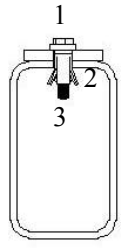

UHB

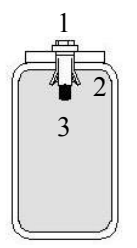

HB

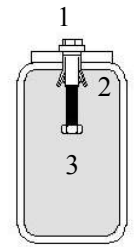

EHB

b)

Fig. 8. Test temperatures in the three type of connections: a) section $150 \times 150 \mathrm{~mm}$ (series 1), b) section $250 \times 150 \mathrm{~mm}$ (series 3 ).

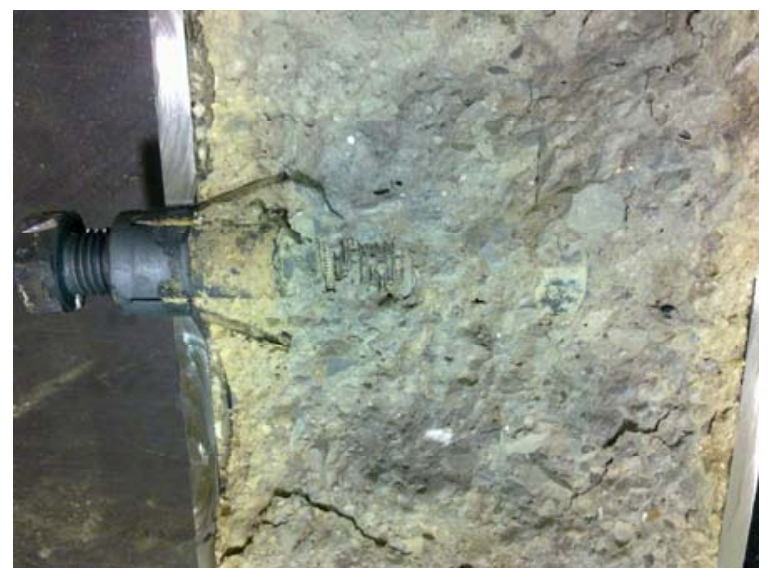

Fig. 9. Specimen after fire exposure. 
Pascual A M, Romero M L, Tizani W. Thermal behaviour of blind-bolted connections to hollow and concrete-filled steel tubular columns. Journal of constructional steel research 2015; 107:137-149.

http://dx.doi.org/10.1016/j.jcsr.2015.01.014

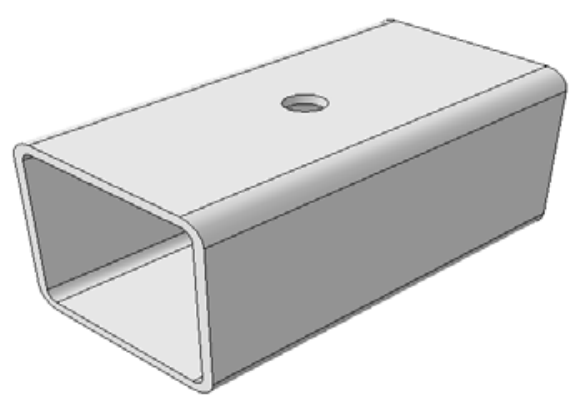

a) Hollow steel section

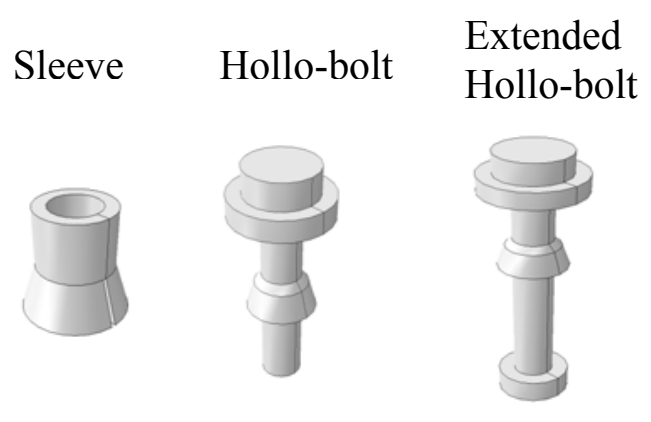

c) Blind-bolt

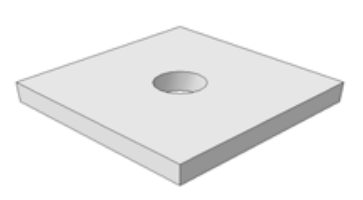

b) Steel plate

Fig. 10. Parts of the connection (FEM).

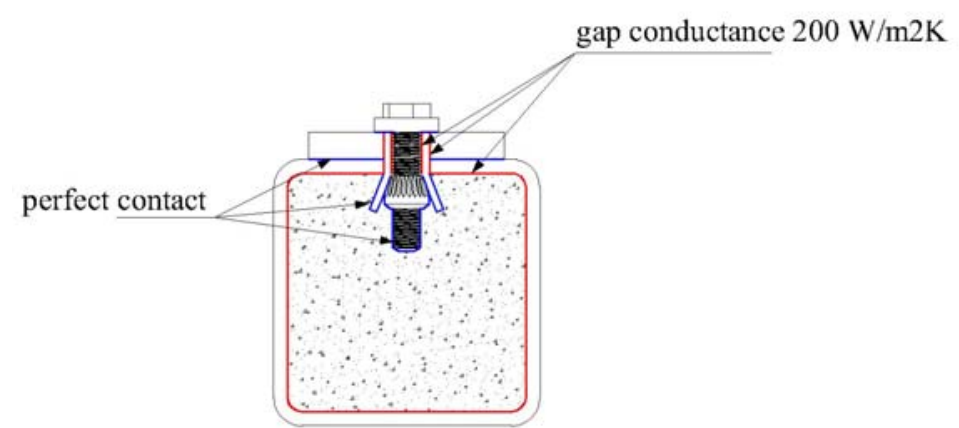

Fig. 11. Gap conductance in interactions. 
Pascual A M, Romero M L, Tizani W. Thermal behaviour of blind-bolted connections to hollow and concrete-filled steel tubular columns. Journal of constructional steel research 2015;107:137-149.

http://dx.doi.org/10.1016/j.jcsr.2015.01.014

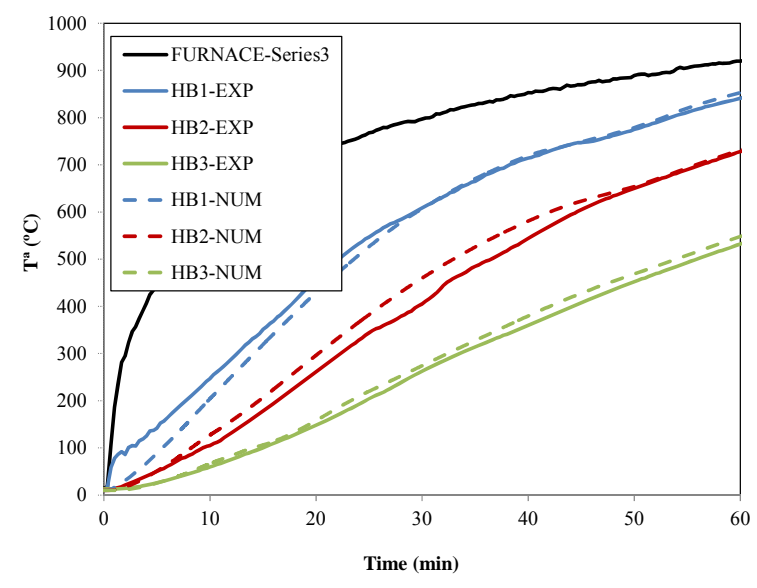

a)

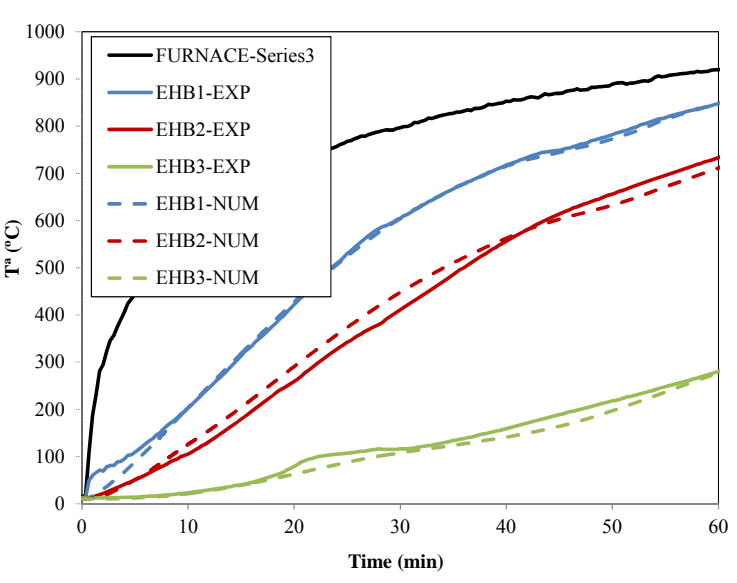

b)

Fig. 12. Bolt temperature in connection to CFST (series 3). Test measurements and FEM model results: a) in HB, b) EHB. 
Pascual A M, Romero M L, Tizani W. Thermal behaviour of blind-bolted connections to hollow and concrete-filled steel tubular columns. Journal of constructional steel research 2015;107:137-149.

http://dx.doi.org/10.1016/j.jcsr.2015.01.014
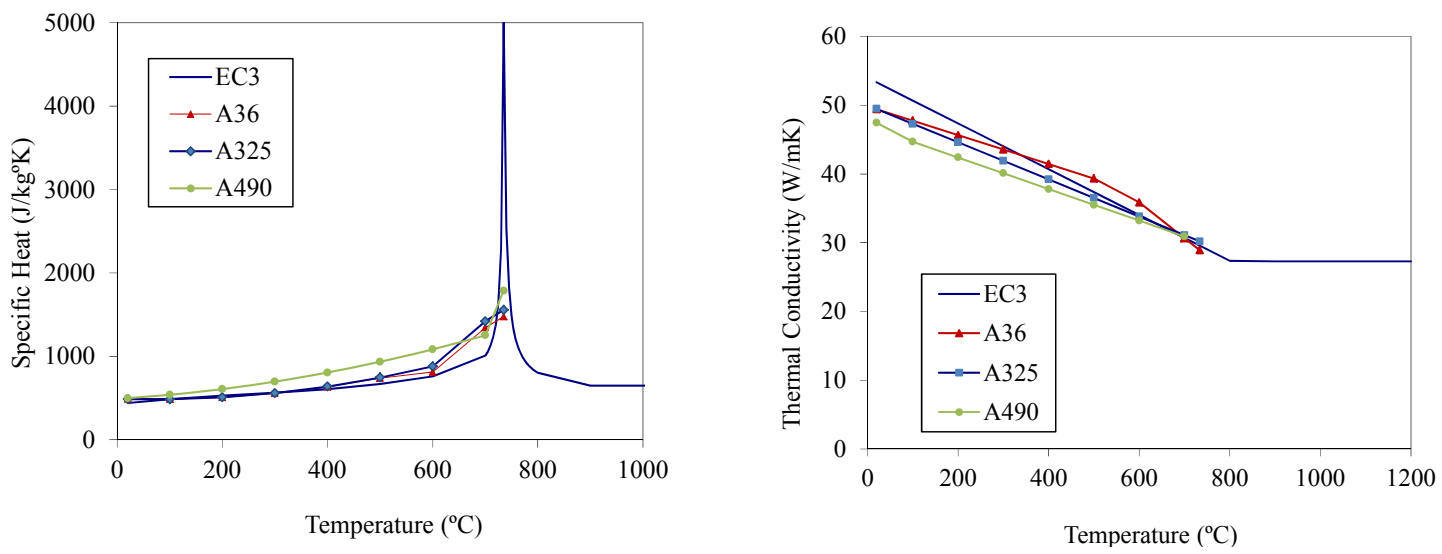

Fig. 13. High-temperature thermal properties of high strength steel of bolts. Comparison between EC3 and experimental data from Kodur [22]

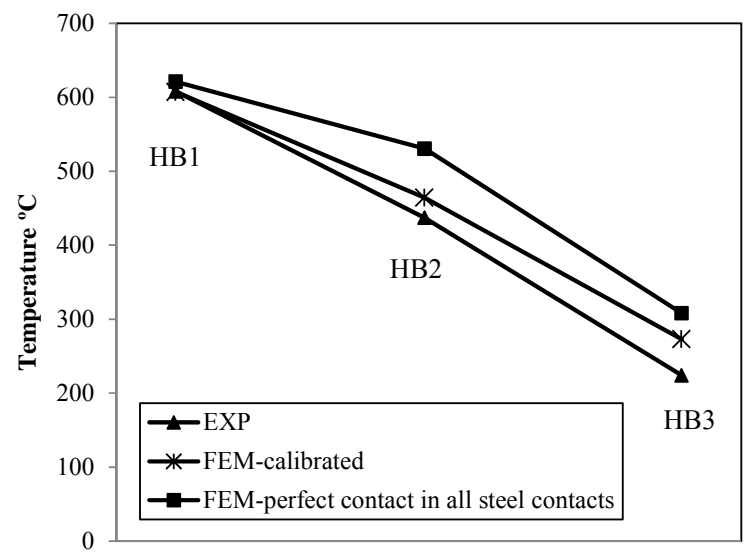

a)

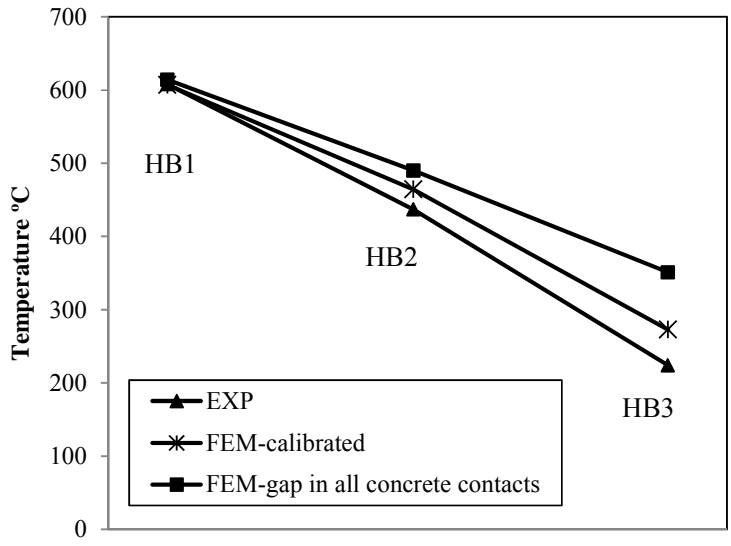

b)

Fig. 14. Gap conductance influence on HB temperature in CFST (series 1) in interactions: a) sleeve-hole surfaces, b) concrete-fastener system. 
Pascual A M, Romero M L, Tizani W. Thermal behaviour of blind-bolted connections to hollow and concrete-filled steel tubular columns. Journal of constructional steel research 2015;107:137-149.

http://dx.doi.org/10.1016/j.jcsr.2015.01.014

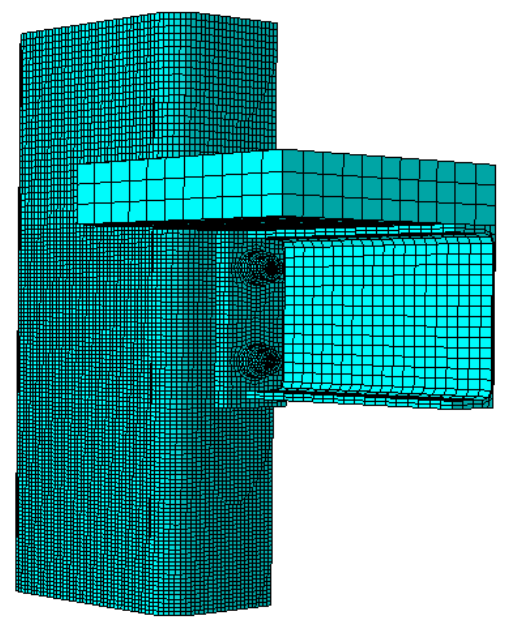

Fig. 15. FEM of the endplate connection between an I-beam and the hollow section column.
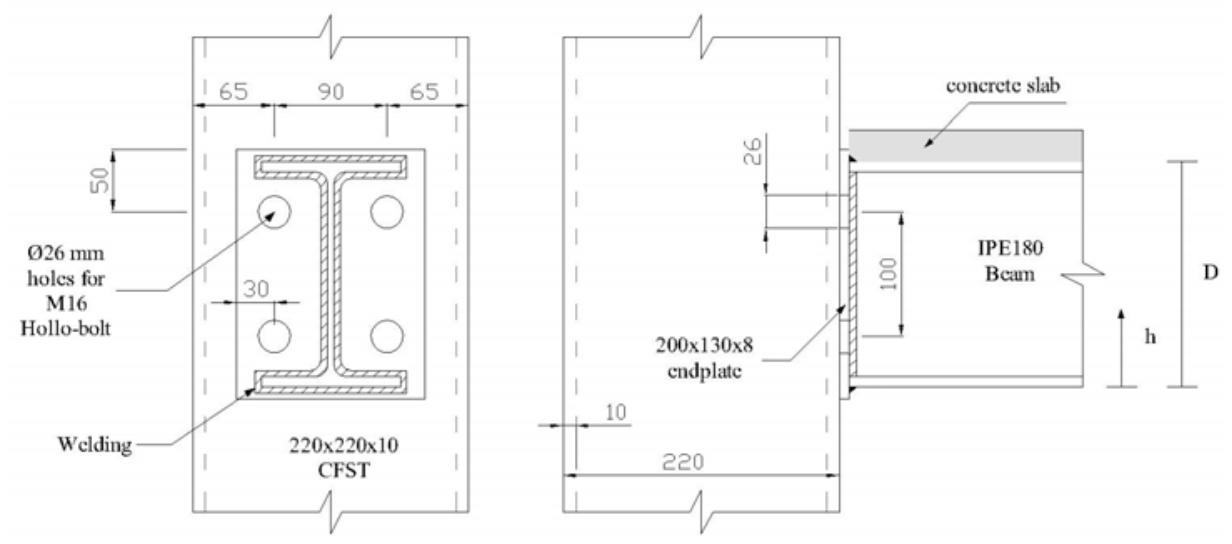

Fig. 16. Geometrical definition of the connection between the I-beam and the hollow section column. 
Pascual A M, Romero M L, Tizani W. Thermal behaviour of blind-bolted connections to hollow and concrete-filled steel tubular columns. Journal of constructional steel research 2015;107:137-149.

http://dx.doi.org/10.1016/j.jcsr.2015.01.014

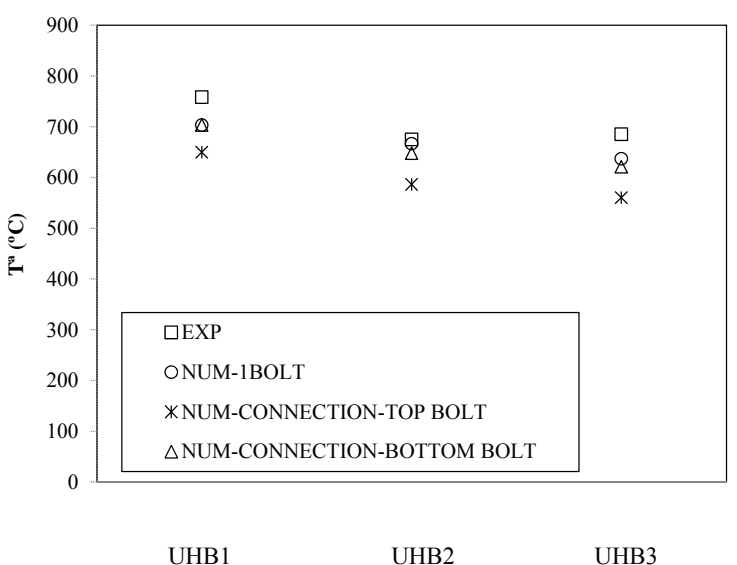

a)

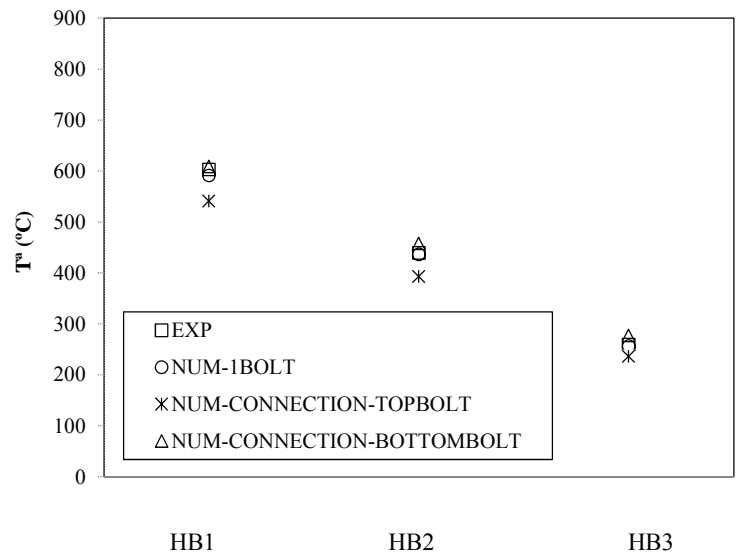

b)

Fig. 17. Bolt temperatures comparison between experimental, FEM of the test specimen and FEM of the whole connection at 30 min of fire exposure: a) in a HSS column, b) in a CFST column.

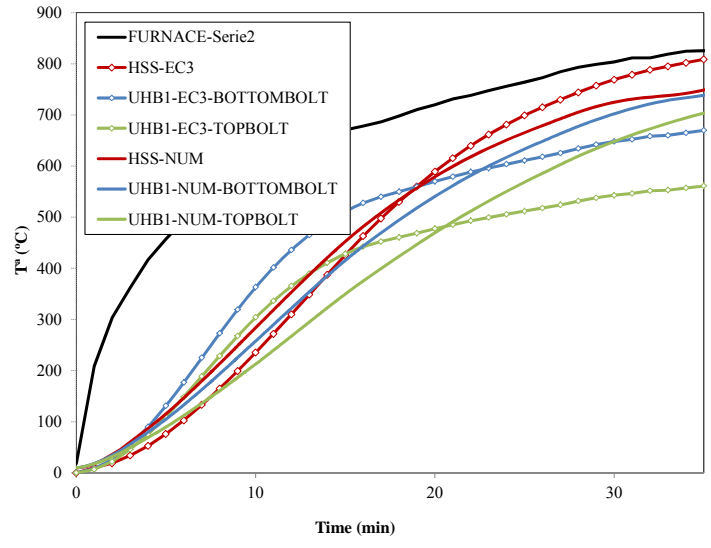

a)

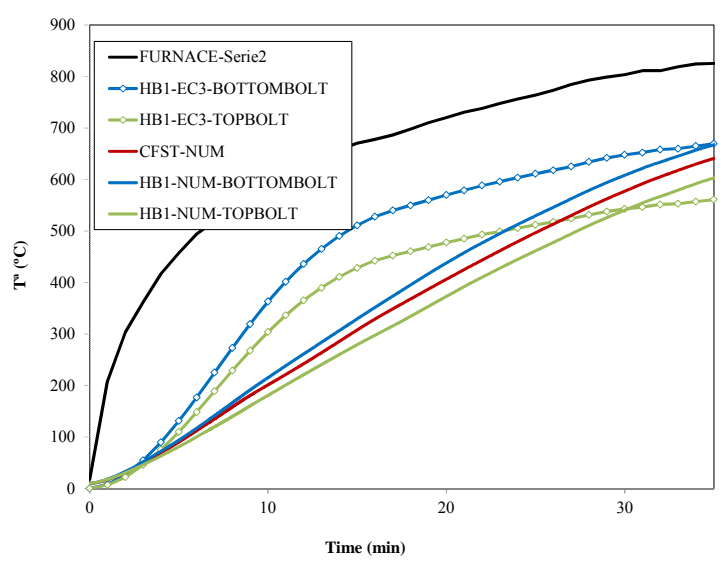

b)

Fig. 18. Temperature in column and head of blind-bolts. Results from EC3 and FEM models for connections I-beam to: a) HSS column, b) CFST column. 
Pascual A M, Romero M L, Tizani W. Thermal behaviour of blind-bolted connections to hollow and concrete-filled steel tubular columns. Journal of constructional steel research 2015;107:137-149.

http://dx.doi.org/10.1016/j.jcsr.2015.01.014

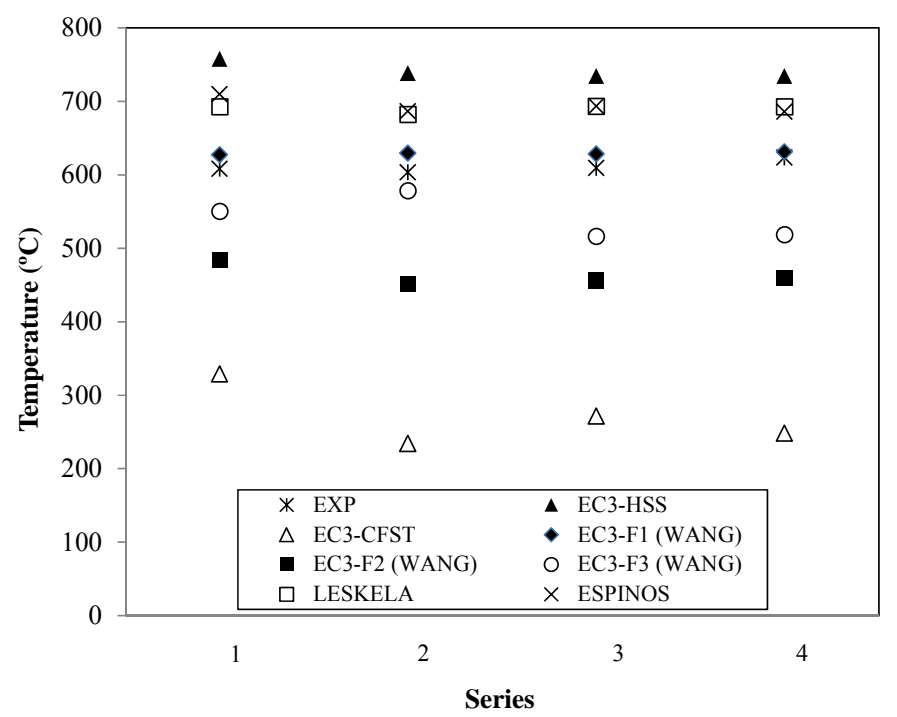

Fig. 19. Temperature in an exposed point of the bolt. Comparison between experiments and simple calculation methods. 
Pascual A M, Romero M L, Tizani W. Thermal behaviour of blind-bolted connections to hollow and concrete-filled steel tubular columns. Journal of constructional steel research 2015; 107:137-149.

http://dx.doi.org/10.1016/j.jcsr.2015.01.014

Table 1. Fire tests specimens.

\begin{tabular}{|c|c|c|c|}
\hline Specimen index & Type of bolt & Shank Length (mm) & $\begin{array}{l}\text { Type of } \\
\text { section }\end{array}$ \\
\hline \multicolumn{4}{|l|}{ Series 1-Section $150 \times 150 \mathrm{t}=8 \mathrm{~mm}$} \\
\hline UHB16-8.8D-150x150x8 & Hollo-bolt & 75 & HSS \\
\hline HB16-8.8D-C30-150x150x8 & Hollo-bolt & 75 & CFST \\
\hline EHB16-8.8D-C30-150x150x8 & Extended Hollo-bolt & 120 & CFST \\
\hline \multicolumn{4}{|l|}{ Series 2-Section $220 \times 220 t=10 \mathrm{~mm}$} \\
\hline UHB16-8.8D-220x220x10 & Hollo-bolt & 75 & HSS \\
\hline HB16-8.8D-C30-220x220x10 & Hollo-bolt & 75 & CFST \\
\hline EHB16-8.8D-C30-220x220x10 & Extended Hollo-bolt & 120 & CFST \\
\hline \multicolumn{4}{|l|}{ Series 3-Section $250 \times 150 \mathrm{t}=10 \mathrm{~mm}$} \\
\hline UHB16-8.8D-250x150x10 & Hollo-bolt & 75 & HSS \\
\hline HB16-8.8D-C30-250x150x10 & Hollo-bolt & 75 & CFST \\
\hline EHB16-8.8D-C30-250x150x10 & Extended Hollo-bolt & 120 & CFST \\
\hline \multicolumn{4}{|l|}{ Series 4-Section $350 \times 150 t=10 \mathrm{~mm}$} \\
\hline UHB16-8.8D-350x150x10 & Hollo-bolt & 75 & HSS \\
\hline HB16-8.8D-C30-350x150x10 & Hollo-bolt & 75 & CFST \\
\hline EHB16-8.8D-C30-350x150x10 & Extended Hollo-bolt & 120 & CFST \\
\hline
\end{tabular}

Table 2. Section Factors.

\begin{tabular}{lccccc}
\hline & $\begin{array}{c}\text { SECTION } \\
\text { FACTOR }\end{array}$ & $\mathbf{1 5 0 \times 1 5 0 \times 8}$ & $\mathbf{2 2 0 \times 2 2 0 \times 1 0}$ & $\mathbf{2 5 0 \times 1 5 0 \times 1 0}$ & $\mathbf{3 5 0 \times 1 5 0 \times 1 0}$ \\
\hline HSS & $\mathrm{A} / \mathrm{V}_{\mathrm{HSS}}$ & 131.02 & 103.85 & 104.27 & 103.35 \\
CFST & $\mathrm{A} / \mathrm{V}_{\text {CFST }}$ & 26.45 & 18.04 & 21.12 & 18.91 \\
Factor 1 (Ding and Wang) & $1 / \mathrm{t}_{1}$ & 66.67 & 66.67 & 66.67 & 66.67 \\
Factor 2 (Ding and Wang) & $1 /\left(\mathrm{t}_{1}+\mathrm{t}_{2}\right)$ & 43.48 & 40.00 & 40.00 & 40.00 \\
Factor 3 (Ding and Wang) & $1_{2} /\left(\mathrm{t}_{1} \mathrm{l}_{1}+\mathrm{t}_{2} \mathrm{l}_{2}\right)$ & 52.63 & 57.14 & 47.62 & 47.62
\end{tabular}


Pascual A M, Romero M L, Tizani W. Thermal behaviour of blind-bolted connections to hollow and concrete-filled steel tubular columns. Journal of constructional steel research 2015;107:137-149.

http://dx.doi.org/10.1016/j.jcsr.2015.01.014

\section{LIST OF FIGURE CAPTIONS}

Fig. 1 Blind-bolts: a) Hollo-bolt type, b) Extended Hollo-bolt type

Fig. 2 Test specimens

Fig. 3 Test specimens before pouring concrete: a) Hollo-bolt, b) Extended Hollo-bolt

Fig. 4 Location of test specimens in furnace

Fig. 5 Thermocouples position in specimens of series 1

Fig. 6 Time-temperature response measured by thermocouples in CFST connection with HB of series 3

Fig. 7 Comparison of bolt temperature between different steel sections in test specimens of HB to CFST connections

Fig. 8 Test temperatures in the three type of connections: a) section 150x150 mm (series 1), b) section 250x150 $\mathrm{mm}$ (series 3)

Fig. 9 Specimen after fire exposure.

Fig. 10 Parts of the connection (FEM).

Fig. 11 Gap conductance in interactions.

Fig. 12 Bolt temperature in connection to CFST (series 3). Test measurements and FEM model results: a) in $\mathrm{HB}, \mathrm{b}) \mathrm{EHB}$.

Fig. 13 High-temperature thermal properties of high strength steel of bolts. Comparison between EC3 and experimental data from Kodur [22]

Fig. 14 Gap conductance influence on HB temperature in CFST (series 1) in interactions: a) sleeve-hole surfaces, b) concrete-fastener system

Fig. 15 FEM of the endplate connection between an I-beam and the hollow section column. 
Pascual A M, Romero M L, Tizani W. Thermal behaviour of blind-bolted connections to hollow and concrete-filled steel tubular columns. Journal of constructional steel research 2015;107:137-149.

http://dx.doi.org/10.1016/j.jcsr.2015.01.014

Fig. 16 Geometrical definition of the connection between the I-beam and the hollow section column.

Fig. 17 Bolt temperatures comparison between experimental, FEM of the test specimen and FEM of the whole connection at 30 min of fire exposure: a) in a HSS column, b) in a CFST column.

Fig. 18 Temperature in column and head of blind-bolts. Results from EC3 and FEM models for connections I-beam to: a) HSS column, b) CFST column.

Fig. 19 Temperature in an exposed point of the bolt. Comparison between experiments and simple calculation methods.

\section{LIST OF TABLES}

Table 1 Fire tests specimens

Table 2 Section Factors. 